Development of Resistance to 4'-Ethynyl-2-Fluoro-2'-Deoxyadenosine (EFdA)

by WT and Nucleoside Reverse Transcriptase Inhibitor Resistant

Human Immunodeficiency Virus Type 1

4

5 Running Title - HIV resistance to EFdA

6

7 Maria E. Cilento ${ }^{a}$, Eleftherios Michailidis ${ }^{b}$, Tatiana V. Ilina ${ }^{c}$, Eva Nagy ${ }^{c}$, Hiroaki Mitsuya ${ }^{d}$,

8 Michael A. Parniak ${ }^{c, \dagger}$, Philip R. Tedburya, Stefan G. Sarafianos ${ }^{a, \#,}$

10 aLaboratory of Biochemical Pharmacology, Department of Pediatrics, Emory University

11 School of Medicine, Atlanta, GA, USA.

12 bLaboratory of Virology and Infectious Disease, The Rockefeller University, New York,

\title{
13 NY
}

14 'Department of Microbiology and Molecular Genetics, University of Pittsburgh School of

15 Medicine, Pittsburgh, PA, USA

16 dDepartment of Refractory Viral Infections, National Center for Global Health \& Medicine

17 Research Institute, Tokyo, Japan; Experimental Retrovirology Section, HIV and AIDS

18 Malignancy Branch, National Cancer Institute, National Institutes of Health, Bethesda,

19 MD, USA; Department of Clinical Sciences, Kumamoto University Hospital, Kumamoto,

20 Japan.

21 tDeceased

22 \# Address correspondence to Stefan G. Sarafianos, ssarafi@emory.edu 
24 4'-ethynyl-2-fluoro-2'-deoxyadenosine (EFdA, MK-8591, islatravir) is a nucleoside

25 reverse transcriptase translocation inhibitor (NRTTI) with exceptional potency against WT

26 and drug-resistant HIV strains. However, HIV resistance to EFdA is not well

27 characterized. We therefore developed resistance to EFdA by serial passages using

28 progressively increasing concentrations of EFdA. The starting virus was either WT or

29 clinically relevant NRTI-resistant viruses K65R, M184V, and D67N/K70R/T215F/K219Q).

30 In all cases, the selected mutations included M184V. Additional mutations in the RT

31 connection domain (R358K and E399K) and one mutation in the RNase $\mathrm{H}$ domain

32 (A502V) were noted. Site-specific mutagenesis validated the role for M184V as the

33 primary determinant for resistance to EFdA; none of the connection domain mutations

34 contributed significantly to phenotypic resistance to EFdA. A novel EFdA resistance

35 mutation was also observed in the background of M184V. The A114S/M184V

36 combination of mutations imparted higher resistance to EFdA ( 24-fold) than M184V (-8-

37 fold) or A114S ( 2-fold) alone. Virus fitness data suggested that A114S affects HIV fitness

38 by itself and in the presence of M184V. This is consistent with biochemical experiments

39 that showed decreases in the enzymatic efficiency $\left(\mathrm{k}_{\mathrm{cat}} / \mathrm{K}_{\mathrm{m}}\right)$ of WT RT vs. A114S (2.1-

40 fold) and A114S/M184V/502V (6.5-fold), whereas there was no significant effect of A502V

41 on RT or virus fitness. The observed EFdA resistance of M184V by itself and in

42 combination with A114S combined with the strong published in vitro and in vivo data,

43 confirm that EFdA is an excellent candidate as a potential HIV therapeutic. 


\section{INTRODUCTION}

46 As of 2018, 37.9 million people worldwide are living with HIV/AIDS, with 1.7 million

47 new HIV infections and 770,000 AIDS-related deaths annually (Mahy et al., 2019).

48 However, AIDS-related morbidity and mortality rates have declined in recent years,

49 largely due to the widespread use of highly-active antiretroviral therapy (HAART) (Mahy

50 et al., 2019). HAART typically consists of a combination of two nucleoside reverse

51 transcriptase inhibitors (NRTIs), along with a nonnucleoside reverse transcriptase

52 inhibitor, protease inhibitor or an integrase inhibitor (Merluzzi et al., 2010). Azidothymidine

53 (AZT), didanosine (ddl), lamivudine (3TC), emtricitabine (FTC), abacavir (ABC), and

54 tenofovir (TFV) are the six NRTIs included in HAART regimens (Eggleton and Nagalli,

55 2020; Menéndez-Arias, 2008; Merluzzi et al., 2010). However, the prevalence of HIV

56 strains resistant to these compounds is rapidly increasing, both in treatment-experienced

57 and newly-infected patients (Clutter et al., 2016; Eggleton and Nagalli, 2020; Larder et

58 al., 1995; Little et al., 2002; Pennings, 2013; Wainberg et al., 2011). High-level resistance

59 to AZT generally requires multiple mutations, including D67N, K70R, T215F, and K219Q

60 (Kellam et al., 1992; Larder and Kemp, 1989; Menéndez-Arias, 2008; Nakata et al., 2007),

61 while an M184I/V mutation grants resistance to both 3TC and FTC (Menéndez-Arias,

62 2008; Petrella et al., 2004; Schinazi et al., 1993; Tisdale et al., 1993). Meanwhile, the

63 K65R mutation imparts some resistance to TFV (Brenner and Coutsinos, 2009; Margot

64 et al., 2002; Miller, 2004; Naeger and Struble, 2006). Also, of great concern is the

65 emergence of virus strains with cross-resistance to multiple NRTIs, which can limit

66 treatment options following viral escape from first-line HAART (Eggleton and Nagalli,

67 2020). M184V strains show resistance to ddl and abacavir, while mutations selected by 
68 AZT are resistant to FTC, and K65R has reduced sensitivity to ddl, 3TC, and FTC (Bazmi

69 et al., 2000; Brenner and Coutsinos, 2009; Menéndez-Arias, 2008; Miller, 2004; Zhang et

70 al., 1994). The currently available NRTIs can also display toxicity and side effects

71 (Brinkman et al., 1999, 1998; Brinkman and Kakuda, 2000; Eggleton and Nagalli, 2020;

72 Lewis et al., 2003). Additionally, the success of antiretroviral regimens at preventing HIV-

731 infection has moved attention to the question of compliance, and increased the interest

74 in therapeutic agents that may be suitable for long interval dosing (Cihlar and Fordyce,

75 2016; Margolis and Boffito, 2015). All of the above are reasons there is a need for the

76 development of novel therapeutic agents.

77 Several studies have investigated a group of novel 4'-substituted NRTIs, the most

78 promising of which is 4'-ethynyl-2-fluoro-2'-deoxyadenosine (EFdA, MK-8591, or

79 islatravir) (reviewed at (Markowitz and Sarafianos, 2018)). EFdA is a deoxyadenosine

80 analog with an ethynyl group at the 4' carbon of the ribose and a fluorine on the 2-position

81 of the adenine base (Kageyama et al., 2011; Kirby et al., 2013, 2011; Nakata et al., 2007).

82 EFdA also retains a 3'-OH, unlike all other HIV NRTIs currently approved for therapeutic

83 use. The presence of the 3'-OH improves the recognition of EFdA as a substrate by

84 cellular kinases such as deoxycytidine kinase (Gallois-Montbrun et al., 2002; Kawamoto

85 et al., 2008a; Nakata et al., 2007) and HIV reverse transcriptase (RT) dNTP binding

86 domain (Michailidis et al., 2014a, 2009; Salie et al., 2016); this may contribute to the

87 efficient production of EFdA-triphosphate (EFdA-TP) and the efficient incorporation of

88 EFdA-monophosphate (EFdA-MP) into nascent HIV DNA during reverse transcription.

89 Deamination of EFdA by cellular enzymes is greatly reduced by the 2-fluorine substitution,

90 increasing the intracellular half-life of the molecule compared to similar non-halogenated 
91 compounds (Kawamoto et al., 2008a; Kirby et al., 2013). The 4'-ethynyl group of EFdA

92 interacts with a hydrophobic pocket in the active site of RT, affecting translocation and

93 extension of the DNA primer, despite the available 3'-OH (Michailidis et al., 2014b;

94 Muftuoglu et al., 2014; Salie et al., 2016). Therefore, EFdA is termed a nucleoside RT

95 translocation inhibitor (NRTTI). EFdA has demonstrated a high level of potency against

96 both WT (wild-type) HIV-1, HIV-2, and NRTI resistant strains (Kawamoto et al., 2008a;

97 Maeda et al., 2014; Oliveira et al., 2017; Wu et al., 2017). The NRTI-resistant virus, K65R,

98 showed hypersensitivity to EFdA (Maeda et al., 2014; Michailidis et al., 2013). EFdA has

99 shown in vivo potency against both HIV and SIV in humanized mouse (Hattori et al., 2009;

100 Shanmugasundaram et al., 2016; Stoddart et al., 2015) and non-human primate models,

101 respectively (Markowitz et al., 2020; Murphey-Corb et al., 2012; Stoddart et al., 2015).

102 EFdA imparts minimal toxicity in the animal models as well as in all in vitro assays, due

103 to minimal inhibition of human DNA polymerases, leading to a high selectivity index

104 (Shanmugasundaram et al., 2016; Sohl et al., 2012; Stoddart et al., 2015). Perhaps most

105 importantly, EFdA is being tested for once-week and once-monthly dosing regimens

106 (Barrett et al., 2018; Grobler et al., 2019; J. et al., 2017, 2016). Taken together, these

107 results suggest that EFdA has great promise as a potential therapeutic agent.

108 Little is known about the capacity of HIV to develop high-level resistance to EFdA, 109 and what mutations may allow the virus to escape inhibition. M184V in RT decreases

110 sensitivity to EFdA (Kawamoto et al., 2008a; Kodama et al., 2001; Maeda et al., 2014;

111 Nakata et al., 2007; Oliveira et al., 2017; Yang et al., 2008). M184V, along with I142V and

$112 \mathrm{~T} 165 \mathrm{R}$, was also selected during passage of WT virus with the parental compound, EdA

113 (Kawamoto et al., 2008a). While an I142V/T165R/M184V virus had a 22-fold increase in 
114 resistance to EFdA relative to $\mathrm{WT}$, it is uncertain whether these mutations would arise

115 during passage of virus in EFdA itself, or if novel mutations conferring even greater

116 resistance are possible. It is also not well understood how resistance to EFdA develops

117 in virus strains with specific pre-existing NRTI resistance mutations, which would be

118 relevant to its potential value as salvage therapy for patients failing first-line HAART.

119 Finally, there is no significant information on the biochemical basis of EFdA resistance

120 and it is not known whether viruses with reduced sensitivity to EFdA would be cross-

121 resistant to the NRTIs currently used in therapy.

122 In this study, we explored the influence of pre-existing NRTI resistance-associated

123 mutations, and identified several novel mutations, associated with development of

124 resistance to EFdA. We selected viruses resistant to EFdA by serial passage of HIV-1, 125 initiating passages with WT virus, or with virus resistant to TFV, 3TC/FTC or AZT. We 126 found that M184V was included in all selected EFdA-resistant strains. Mutations also

127 appeared in the RT connection domain (R358K and E399K) and the RNase H domain 128 (A502V), although these changes did not appear to compensate for loss of fitness nor 129 significantly affect resistance when alone. We were able to identify a double mutant virus 130 with a moderate-level of resistance, A114S/M184V ( 25-fold). 


\section{RESULTS}

Virus breakthrough during serial passage of viruses in increasing EFdA

134 concentrations. Serial passages were initiated by infecting MT-2 cells with WT (xxLAI),

$135 \mathrm{~K} 65 \mathrm{R}, \mathrm{M} 184 \mathrm{~V}$ or $\mathrm{D} 67 \mathrm{~N} / \mathrm{K} 70 \mathrm{R} / \mathrm{T} 215 \mathrm{~F} / \mathrm{K} 219 \mathrm{Q}$ stock virus in the presence of $\mathrm{EFdA}$ and

136 followed as described in Materials and Methods. All EFdA-selected viruses, regardless of

137 the initial strain or number of passages, induced $\geq 75 \%$ syncytia formation in untreated

138 MT-2 cells within 7 days of infection.

139 The ability of the viruses to grow in the presence of EFdA was assessed by time

140 to viral breakthrough (defined as $75 \%$ syncytia formation) at each passage. This time to

141 breakthrough and the concentration of EFdA in each passage is shown in Figure 1. For

$142 \mathrm{WT}, \mathrm{M} 184 \mathrm{~V}$, and D67N/K70R/T215F/K219Q, virus breakthrough typically occurred after

143 approximately 7 days. As EFdA concentrations were raised in passages 8 and 9 , time to

144 virus breakthrough increased, until virus replication was no longer observed in passage

145 10. Passage 10 corresponded to an EFdA concentration of $550-800 \mathrm{nM}$ (Figure $1 \mathrm{~A}, \mathrm{C}$ 146 and D).

147 The behavior of K65R deviated from the other mutants studied in two ways. Firstly,

148 there was a reduction in the time to breakthrough from passages $1-4$, likely associated

149 with the loss of K65R that was lost as early as $P_{2}$ (data not shown) and was not detected

150 at passage 6 (Table 1, Figure 1), which confers hypersensitivity to EFdA (Michailidis et

151 al., 2013). The time to breakthrough then increased as EFdA concentrations were raised,

152 as seen with other viruses. These passages eventually terminated at passage 16 at a

153 final concentration of $\sim 35,000 \mathrm{nM}$ EFdA (Figure 1B). 
In every case, the passaged viruses were able to replicate in greater EFdA

155 concentrations than the parental virus, indicating that some degree of EFdA resistance

156 had developed. The most significant resistance appeared in the passages initiated with

157 K65R virus.

158 Infectivity of EFdA-passaged virus supernatants. To determine whether the

159 passaged viruses had undergone significant changes in infectivity, independent of their

160 potential resistance to EFdA, the infectivity of passaged isolates was compared to the

161 infectivity of the unpassaged starting virus $\left(P_{0}\right)$, using the P4R5 MAGI reporter cell line in

162 the absence of EFdA. For WT-, K65R- and M184V-derived viruses, the passaged strains

163 demonstrated higher infectivity than the unpassaged $P_{0}$ (Figure $\left.2 A-C\right)$. The

$164 \mathrm{D} 67 \mathrm{~N} / \mathrm{K} 70 \mathrm{R} / \mathrm{T} 215 \mathrm{~F} / \mathrm{K} 219 \mathrm{Q}$ viruses showed similar replication efficiency to the parental

165 virus (Figure 2D). These increases in viral infectivity suggest that an increase in overall

166 viral fitness may contribute to enhanced replication in the presence of EFdA for WT-,

167 K65R- and M184V-derived viruses.

168 Dose response of EFdA-passaged viruses to EFdA. To evaluate the degree of 169 resistance selected in the passaging experiments, sensitivity to EFdA was determined for

170 virus supernatants from $\mathrm{P}_{6}$ onwards. Data are presented for the viruses obtained from $\mathrm{P}_{6}$,

$171 \mathrm{P}_{9}$ and, in one case, $\mathrm{P}_{10} . \mathrm{P}_{6}$ was the first passage for which extensive sequencing analysis

172 was performed, $\mathrm{P}_{9}$ was the effective endpoint for the WT-, M184V- and

$173 \mathrm{D} 67 \mathrm{~N} / \mathrm{K} 70 \mathrm{R} / \mathrm{T} 215 \mathrm{~F} / \mathrm{K} 219 \mathrm{Q}$-derived viruses, and $\mathrm{P}_{10}$ was chosen as the endpoint for the

174 K65R-derived strain. For each of the viruses studied, the later passage viruses

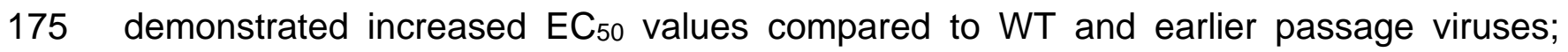

176 however, the final $\mathrm{EC}_{50}$ increased compared to starting, as expected (Figure 3 A-D). 


\section{Development of amino acid mutations in reverse transcriptase during serial}

178 passage of viruses with EFdA. Clonal sequencing confirmed the identity of the $\mathrm{P}_{0}$ stock

179 viruses. Similar sequencing was carried out on clones from various passages to identify 180 any changes in RT that may have arisen during replication in the presence of EFdA. Table

1811 summarizes data for $\mathrm{P}_{6}$ and $\mathrm{P}_{9}$ isolates for all parental viruses, and viruses from $\mathrm{P}_{6}, \mathrm{P}_{9}$, 182 and $\mathrm{P}_{10}$ for K65R.

183 The WT $\mathrm{P}_{6}$ population sequencing revealed only $\mathrm{M} 184 \mathrm{I}$ (Table 1); by $\mathrm{P}_{9}$, 184 approximately $30 \%$ of sequences were M184I, $30 \%$ were M184I/E399K, and the 185 remainder was divided between M184V and WT. Consistent with the initial passage data, 186 sequencing data showed that all clones of the K65R $\mathrm{P}_{6}$ virus reverted the K65R mutation 187 back to WT. The reversion occurred rapidly, as K65R was not seen in the $\mathrm{P}_{2}$ population. 188 Over $90 \%$ of clones additionally contained M184I, with the remainder M184V. Sequencing 189 data also showed that the proportion of $\mathrm{M} 184 \mathrm{~V}$ increased to one-quarter of the 190 population by $\mathrm{P}_{8}$. The virus harvested following $\mathrm{P}_{9}$ had a more heterogeneous population, 191 with most sequences containing M184V/A502V or M184I. By $\mathrm{P}_{10}$, the diversity decreased 192 dramatically, and A114S/M184V/A502V became the dominant sequence. A114S/M184V 193 and A114S/A502V were found at much lower frequency. The A114S/M184V/A502V

194 mutation remained dominant through subsequent passages, reaching $100 \%$ of 195 sequences in $\mathrm{P}_{12}$ and $\mathrm{P}_{13}$

196 The only novel mutation gained during passages that started with M184V was

197 R358K, which became increasingly dominant as passaging progressed. Sequencing of 198 the virus that broke through $\mathrm{P}_{10}$ revealed that two-thirds of the sequences had R358K 
199 alone, while $27.3 \%$ of the population contained a combination of R358K and A502V in 200 addition to the present M184V mutation.

201 Passage of the D67N/K70R/T215F/K219Q virus led to the rapid emergence of 202 M184V (dominant in passage 6). This was joined by E399K (M184V/E399K was dominant 203 in passage 9) in late passages. None of the starting mutations were lost during passage. 204 These passaging and sequencing experiments revealed a variety of mutations 205 associated with EFdA resistance. Independent of the starting sequence, resistance was 206 associated with mutations at residue M184, and the highest levels of resistance required 207 an additional A114S mutation.

Sensitivity of molecular clone viruses to EFdA. To confirm that the mutations

209 identified by sequencing were capable of conferring resistance to EFdA, molecular clones

210 representing the major mutant genotypes that developed during passage in EFdA were

211 produced in a WT (NL4-3) backbone and characterized for their infectivity relative to WT.

212 Individual mutants A114S, R358K, E399K, and A502V had no effect on resistance to

213 EFdA. The only resistant individual mutant was M184V, which conferred about 8-fold 214 resistance to EFdA, consistent with previous reports (Kawamoto et al., 2008b; Oliveira et 215 al., 2017) (Figure 4). Addition of the A114S further increased the EFdA resistance, as 216 seen in the cases of A114S/M184V (24-fold), A114S/M184V/R358K (28-fold), and 217 A114S/M184V/A502V (25-fold). The R358K or A502V mutations by themselves had 218 almost no effect on EFdA resistance (Figure 4). These data confirm that several of the 219 mutations identified in the passaged viruses do confer resistance to EFdA, with the 220 highest levels of resistance found in the concomitant presence of the A114S and M184V 221 mutations. 
Replication characteristics of molecular clone viruses. To determine if the

223 mutations had an impact on viral fitness, viruses were tested in single cycle replication

224 assays. There were no statistically significant differences in the fitness of connection

225 domain mutants R358K and E399K or RNase H mutant A502V. However, there was a 226 decrease in fitness of the A114S-containing mutants, A114S/M184V and $227 \mathrm{~A} 114 \mathrm{~S} / \mathrm{M} 184 \mathrm{~V} / \mathrm{A} 502 \mathrm{~V}$, as compared to WT (Figure 5). This is consistent with the 228 biochemical data below, where a decrease in specific activity was observed for the RTs 229 with the corresponding mutations.

230 Steady State Kinetics and EFdA susceptibility of Mutant Reverse

231 Transcriptases. In order to further understand the effect of the mutations on the DNA 232 polymerase activity of RT, we performed steady state kinetics to determine the catalytic 233 efficiency ratio, $\mathrm{k}_{\mathrm{ca}} / \mathrm{K}_{\mathrm{m}}$, for various $\mathrm{RT}$ mutants. We cloned, expressed, and purified the 234 mutant RTs listed in Table 2. We found that in the presence of the A114S mutation there 235 was a consistent decrease in the catalytic efficiency ratio $\mathrm{k}_{c a t} / \mathrm{Km}_{\mathrm{m}}$ compared to WT RT: a 2362.1 decrease for $\mathrm{A} 114 \mathrm{~S}$ and a 6.5 for $\mathrm{A} 114 \mathrm{~S} / \mathrm{M} 184 \mathrm{~V} / \mathrm{A} 502 \mathrm{~V}$. Of note, the $\mathrm{k}_{\text {cat }} / \mathrm{K}_{\mathrm{m}}$ for the $237 \mathrm{~A} 502 \mathrm{~V}$ and M184V single mutants was comparable to that of the WT enzyme (Table 2). 


\section{DISCUSSION}

NRTIs are the most widely used therapeutics to treat HIV infection. As such, NRTI-

240 resistant HIV variants are becoming increasingly prevalent in the HIV-1-infected

241 population. EFdA has potential as salvage therapy for patients infected with NRTI-

242 resistant mutants of HIV and as first line therapy for naïve HIV-infected individuals, owing

243 to its potential suitability for long interval dosing. As such, we were interested in identifying

244 and characterizing EFdA-resistant mutations that might arise during exposure of WT HIV,

245 and especially NRTI-resistant virus variants, to EFdA.

246 Regardless the type of starting genotype virus, M184I/V ended up consistently to

247 be the predominant mutation that arose during passages through EFdA. The M184V

248 mutation confers high-level resistance to both 3TC and FTC (Petrella et al., 2004;

249 Schinazi et al., 1993; Tisdale et al., 1993) (Sarafianos et al., 1998), but only low-level

250 resistance to EFdA (Kawamoto et al., 2008a; Maeda et al., 2014). Our present data

251 confirm the latter, with M184V conferring only 8-fold resistance to EFdA. Interestingly,

$252 \mathrm{M} 184 \mathrm{~V}$ is also the primary resistance mutation selected during serial passage of WT HIV

253 with related compounds EdA and Ed4T suggesting that M184 is critical to the activity of

254 4'-ethynyl modified nucleoside analogues (Kawamoto et al., 2008a; Nitanda et al., 2005).

255 Due to the widespread use of 3TC and FTC in HIV treatment, the M184V mutation

256 is already present in many treatment-experienced patients. Since this mutation confers

257 relatively low-level resistance to EFdA, we were interested to determine whether M184V

258 virus could develop increased resistance during replication in the presence of EFdA.

259 The $\mathrm{D} 67 \mathrm{~N} / \mathrm{K} 70 \mathrm{R} / \mathrm{T} 215 \mathrm{~F} / \mathrm{K} 219 \mathrm{Q}$ mutant, is highly resistant to AZT (Kellam et al.,

260 1992; Larder and Kemp, 1989). Similar to another AZT-resistant mutant, M41L/T215Y, 
261 that was previously shown to display marginal resistance to EFdA (Kawamoto et al., 262 2008a), we found that D67N/K70R/T215F/K219Q had a 1.8-fold increase in EFdA 263 resistance compared to WT. As we have previously shown, the excision unblocking 264 mechanism of resistance is not a major challenge for EFdA: although EFdA can indeed 265 be excised, the efficiency of reincorporation is so high, that the net result is no significant 266 overall excision (Michailidis et al., 2014b). The K65R mutation confers resistance to TFV 267 and is the mutation responsible for virological failure in TFV-based therapies. K65R is 268 also cross-resistant or selected during therapy with ABC, ddl, and 3TC/FTC (Bazmi et al., 269 2000; Brenner and Coutsinos, 2009; Eggleton and Nagalli, 2020; Miller, 2004; Naeger 270 and Struble, 2006; Zhang et al., 1994). We previously showed that the K65R variant is 271 hypersensitive to EFdA, with up to five-fold lower $\mathrm{EC}_{50}$ compared to WT (Kawamoto et 272 al., 2008a; Maeda et al., 2014; Michailidis et al., 2013). Our current results are consistent 273 with this finding, as the K65R mutation was rapidly lost during passage in EFdA. The rapid 274 reversion of this mutation leads not only to a reduction in sensitivity to EFdA, but also 275 confers increased replication fitness to the virus. Collectively, the K65R, M184V, and $276 \mathrm{D} 67 \mathrm{~N} / \mathrm{K} 70 \mathrm{R} / \mathrm{T} 215 \mathrm{~F} / \mathrm{K} 219 \mathrm{Q}$, possess either increased sensitivity to EFdA, or slight (less 277 than 10-fold) increased resistance.

278 Our results demonstrate the difficulty of selecting for resistance to EFdA. Even 279 when starting the passages using different starting genotypic backgrounds, there was 280 consistent appearance of the M184V mutation that by itself gave modest resistance 8281 fold. Here we have identified a novel EFdA resistance mutation, A114S, that when added 282 to M184V enhances EFdA resistance to about 25-fold. Importantly, this mutation, 283 especially in the background of M184V, appears to have a negative impact on viral fitness. 
284 This was confirmed using both viral fitness data as well as biochemical data with purified 285 enzymes (Figure 5 and table 2). Specifically, it seems that the decrease in fitness is likely 286 due to decreased binding of incoming dNTPs, as judged in all cases where A114S 287 mutation was present. As both 184 and 114 residues are located at opposing sides of the 288 EFdA binding pocket, we speculate that the bulkier mutant residues (V184 and S114) 289 impinge into the substrate envelope of the 4'-ethynyl pocket, thus causing decrease in 290 dNTP binding (increase in $\mathrm{K}_{\mathrm{m}}$ ) and decrease in viral fitness.

291 In general, it appears that the development of EFdA resistance begins with 292 mutations in the binding site; in our experiments, as well as in a previous report (Maeda 293 et al., 2014), the initial mutation was M184I. We found that M184I was replaced at later 294 passages by M184V, a mutation with superior replication capacity (Frost et al., 2000; 295 Keulen et al., 1997; Schuurman et al., 1995). RT connection domain mutations (R358K 296 and E399K) were selected at later passages. These residues are proximal to G359-A360 297 and K395-E396, respectively, in the RNAse H primer grip region that interacts with the 298 DNA primer strand (Julias et al., 2003; Sarafianos et al., 2001). While R358 may form a 299 weak hydrogen bond with the phosphate backbone of the primer strand (Ding et al., 300 1998), any effect of R358K or E399K will only be minor, and likely through minor 301 structural adjustments affecting the position of nearby residues. Studies have 302 demonstrated that R358K is selected both in NRTI-treated patients and during passage 303 with NRTIs in tissue culture (Brehm et al., 2007; Delviks-Frankenberry et al., 2008; 304 Lengruber et al., 2011; Tachedjian et al., 1998; von Wyl et al., 2010). However, any 305 contribution of R358K to NRTI resistance is minimal and clinically it is likely selected as 306 a pre-existing polymorphism, as it is present in $7.1 \%$ of treatment-naïve patients (Rhee, 
307 2003; von Wyl et al., 2010). E399 is located within a cluster of several highly conserved 308 tryptophan residues that are involved in RT dimerization (Chiang et al., 2012; Tachedjian

309 et al., 2003), so E399K may have very small effects on stabilizing the heterodimer RT.

310 We found no significant variation in EFdA resistance between M184V/E399K or

$311 \mathrm{M} 184 \mathrm{~V} / \mathrm{R} 358 \mathrm{~K}$ and M184V alone. These results indicate that neither R358K nor E399K

312 contribute directly to EFdA resistance. We initially considered that these mutations might

313 provide a fitness benefit to the mutants when added to the M184V background, potentially

314 compensating for fitness costs associated with the acquisition of M184V (Wainburg, 2004;

$315 \mathrm{Xu}$ et al., 2011). However, we did not observe improved fitness in our single round 316 replication assays.

317 A further late-appearing mutation was A502V, which emerged during passaging of $318 \mathrm{~K} 65 \mathrm{R}$. Unlike R358 and E399 that are located in the connection subdomain of RT, A502 319 is located in the RNase H domain, near residues Y501 and I505, both of which interact 320 with the DNA primer strand as part of the RNAse H primer grip region (Sarafianos et al., 321 2001). Again, A502V does not appear to contribute to EFdA resistance, as the $322 \mathrm{M} 184 \mathrm{~V} / \mathrm{A} 502 \mathrm{~V}$ clone did not have significantly lower sensitivity than M184V/E399K or $323 \mathrm{M} 184 \mathrm{~V} / \mathrm{R} 358 \mathrm{~K}$. The M184V/A502V mutant subsequently acquired an A114S mutation,

324 which coincided with a significant increase in EFdA resistance. While the A114S mutation 325 has never been reported in the context of EFdA resistance, it is associated with resistance 326 to both foscarnet and AZT in vitro, but may increase sensitivity to AZT in vivo by affecting

327 the enzyme processivity and pyrophosphorolysis rates (Arion et al., 2000; Larder et al., $3282006,1987)$. 
A114 is part of a group of residues in the dNTP/EFdA-TP binding site, including

$330 \mathrm{~A} 113, \mathrm{Y} 115, \mathrm{Q151}$, and M184, which interact with the 3'-OH of incoming dNTPs (Cases-

331 Gonzalez and Menéndez-Arias, 2005; Harris et al., 1998; Van Cor-Hosmer et al., 2012).

332 While the main chain amide of A114 interacts with the dNTP triphosphate, the alanine

333 side chain protrudes towards the $3^{\prime}-\mathrm{OH}$ of the sugar moiety (Cases-Gonzalez and

334 Menéndez-Arias, 2005; Huang et al., 1998; Menéndez-Arias, 2008). The A114S mutation

335 has a longer side chain, which extends closer to the 3'-OH of an incoming dNTP and

336 reduces the available space in the binding pocket and can thus increase selectivity for

337 the correct dNTP. Consistent with our data, the A114S mutation was also previously

338 observed to decrease the DNA polymerase activity of RT (Cases-Gonzalez and

339 Menéndez-Arias, 2005; Van Cor-Hosmer et al., 2012). Furthermore, the side chain of

340 A114 forms part of a hydrophobic pocket, along with Y115, M184, F160, and D185, which

341 interacts with the 4'-ethynyl group of molecules such as EFdA (Salie et al., 2016) and

342 4'Ed4T-TP (Michailidis et al., 2009; Yang et al., 2008). M184V may alter the shape of this

343 pocket, causing steric hindrance with the 4'-ethynyl and reducing the affinity of RT for

344 molecules with this functional group (Yang et al., 2008). A114S may also alter the shape

345 at the opposite side of the hydrophobic pocket. By itself, the A114S molecular clone

346 demonstrated a modest increase in EFdA resistance relative to WT. Higher resistance

347 ( 24-fold) was observed when A114S and M184V appeared together. This could be due

348 to both synergistically interfering with the hydrophobic pocket, thus disrupting the 4'-

349 ethynyl from stabilizing in the hydrophobic pocket and greatly reducing the enzyme affinity

350 for EFdA. It is also possible that the A114S mutation contributes to a reversal of the

351 translocation impairment imposed by EFdA after its incorporation in the primer terminus. 
352 Nevertheless, A114S-containing mutants may not be a major problem in patients; A114

353 mutations are rarely seen in clinical samples. Indeed, as of June 2012, only 21 sequences

354 in the Stanford HIV Drug Resistance Database have mutations at this residue, only one

355 of which is A114S (Rhee, 2003).

356 A major concern when introducing any new NRTI to clinical use is the potential for

357 cross-resistance with current NRTIs. Our results confirm that EFdA drives the selection

358 of $\mathrm{M} 184 \mathrm{I} / \mathrm{V}$, producing virus with high-level cross-resistance to both $3 \mathrm{TC}$ and FTC.

359 However, EFdA is a potent inhibitor, even against M184I/V mutants; it retains the ability

360 to inhibit replication of these mutants at therapeutic doses. Conversely, M184I/V

361 increases AZT sensitivity in both WT and AZT-resistant backgrounds (Boucher et al.,

362 1993; Boyer et al., 2002; Larder et al., 1995; Tisdale et al., 1993).

363 The selection and characterization of EFdA resistance mutations through viral

364 passage revealed the difficulty in identifying mutations that confer high-level resistance

365 to EFdA. Although mutations at M184 were selected, they conferred less than 10-fold

366 resistance. In our experiments, the development of greater resistance to EFdA required

367 the combination of multiple mutations, including both M184V and A114S. These changes

368 allowed for enhanced resistance to EFdA.

369 In summary, the data presented here demonstrate that a significant barrier exists

370 to HIV developing high-level resistance to EFdA. In addition, viruses that do develop high-

371 level resistance to EFdA become highly sensitized to other NRTIs. These results

372 demonstrate that EFdA has potential to be a highly effective therapeutic.

373 


\section{MATERIALS AND METHODS}

376 Reagents. EFdA was synthesized by Life Chemicals (Burlington ON, Canada).

377 Stock solutions (10 mM) of EFdA was prepared in dimethyl sulfoxide (DMSO) and stored

378 in aliquots at $-20^{\circ} \mathrm{C}$. MT-2 cells (Boufford and Spongberg, 1983; Charneau et al., 1994;

379 Haertle et al., 1988) were cultured in RPMI 1640 medium (Mediatech Inc, Manassas, VA),

380 supplemented with 10\% fetal bovine serum (FBS) (HyClone, Logan, UT), 2 mM L-

381 glutamine (Mediatech Inc) and $100 \mathrm{U} / \mathrm{ml}$ penicillin, $100 \mu \mathrm{g} / \mathrm{ml}$ streptomycin (Mediatech

382 Inc). P4-R5 MAGI cells were cultured in DMEM (Mediatech Inc), supplemented with 10\%

383 FBS, $2 \mathrm{mM}$ L-glutamine, $100 \mathrm{U} / \mathrm{ml}$ penicillin, $100 \mu \mathrm{g} / \mathrm{ml}$ streptomycin and $1 \mu \mathrm{g} / \mathrm{mL}$

384 puromycin. HEK-293 cells (Graham et al., 1977) and HEK-293/17 (Pear et al., 1993) were

385 cultured in DMEM supplemented with 10\% FBS, L-glutamine and penicillin/streptomycin.

386 TZM-GFP cells (Derdeyn et al., 2000; Platt et al., 2009, 1998; Rosa et al., 2015; Takeuchi

387 et al., 2008; Wei et al., 2002) were cultured in DMEM (Corning) supplemented with $10 \%$

388 Serum Plus, $2 \mathrm{mM}$ L-glutamine (ThermoFisher, Waltham, MA), $100 \mathrm{U} / \mathrm{ml}$

389 penicillin/streptomycin (ThermoFisher). Jurkat LTR-GFP CCR5+ Cells (JLTRG-R5)

390 (Kutsch et al., 2004; Ochsenbauer-Jambor et al., 2006) were cultured in RPMI 1640

391 medium (Cytiva Life Sciences, Marlborough, MA) supplemented with 10\% FBS and 100

$392 \mathrm{U} / \mathrm{mL}$ penicillin/streptomycin.

393 Generation of virus stocks and molecular clones. Initial K65R, M184V, and

$394 \mathrm{D} 67 \mathrm{~N} / \mathrm{K} 70 \mathrm{R} / \mathrm{T} 215 \mathrm{~F} / \mathrm{K} 219 \mathrm{Q}$ viruses were generated by site-directed mutagenesis on an

395 xxLAI HIV-1 backbone using the QuikChange XL Site-Directed Mutagenesis kit (Agilent

396 Technologies Inc, Santa Clara, CA), according to the manufacturer's protocols.

397 Subsequently, $6 \times 10^{5} 293-\mathrm{T}$ cells were transfected with $10 \mu \mathrm{g}$ of viral DNA using the 
398 PrimeFectimine Mammalian Transfection Reagent (PrimGen, Oak Park, IL). After 72 h

399 incubation, HEK-293/T cell supernatants were harvested, filtered and used to infect 1.8

$400 \times 10^{6}$ MT-2 cells. Infected MT-2 cells were incubated at $37^{\circ} \mathrm{C}\left(5 \% \mathrm{CO}_{2}\right)$, inspected daily

401 and infectious virus harvested at $\geq 50 \%$ syncytia formation. Emory's Cloning Core was

402 used to make individual mutants in the backbone of NL4.3. These mutant viruses were

403 made using HEK-293/17 cells that were transfected with $6 \mu \mathrm{g}$ of viral DNA using

404 Xtreme-GENE HP (Roche, Basel, Switzerland) Transfection reagent. After $48 \mathrm{~h}$

405 incubation HEK-293/17 cell supernatants were harvested, concentrated overnight with a

406 Lenti-X concentrator (Clontech) according to the manufacturer's protocol.

407 Determination of TCID $_{50}$ values and p24 content. TCID 50 values were

408 determined by infecting $5 \times 10^{4}$ MT-2 cells per well, in 96-well flat-bottom plates, with four-

409 fold serial dilutions of virus stock. Three replicates were performed for each virus. Infected

410 plates were inspected daily for syncytia formation; every three days, half of the

411 supernatant was replaced with fresh media. The assay was terminated when no

412 additional syncytia formation was noted for two days. The TCID 50 was then calculated

413 using the Reed-Muench method (Reed and Muench, 1938). The p24 content of each

414 virus stock was determined using the HIV-1 p24 ${ }^{\mathrm{CA}}$ Antigen Capture Assay kit (SAIC-

415 Frederick, Frederick, MA).

416 Serial passage for selection of resistant virus. MT-2 cells were suspended at

$4172.5 \times 10^{5}$ cells per $\mathrm{mL}$ in $10 \mathrm{~mL}$ of media containing $\mathrm{EFdA}$. Initial EFdA concentrations

418 were chosen based on the $\mathrm{EC}_{50}$ of WT stock virus $(8.6 \mathrm{nM})$, with a similar amount chosen

419 for the K65R virus and slightly higher concentrations for the D67N/K70R/T215F/K219Q

$420(10 \mathrm{nM})$ and M184V (12 nM) strains. Passages were initiated by immediately adding 200 
421 TCID 50 of the appropriate unpassaged $\left(P_{0}\right)$ virus stock to the cells and mixing gently.

422 Untreated cultures were initiated by infecting $2.5 \times 10^{5} \mathrm{MT}-2$ cells per mL with 200 TCID 50

423 of $\mathrm{P}_{0}$ virus stock in $10 \mathrm{~mL}$ drug-free media. All passages and untreated cultures were

424 grown in T-25 tissue culture flasks. Every $2-3$ days, cells were mixed and replaced with

425 fresh media containing the appropriate concentration of EFdA. Cultures were visually

426 inspected every $1-2$ days for the presence of syncytia. At $\geq 75 \%$ syncytia formation,

427 culture supernatants were harvested, concentrated using Amicon Ultra Ultracel - 100K

428 centrifugal filters (Millipore, Carrigtwohill, Co. Cork, Ireland) and syringe-filtered through

$4290.22 \mu \mathrm{M}$ filters (Millipore). The p24 content of the resulting first passage $\left(\mathrm{P}_{1}\right)$ supernatant

430 was determined as described above. This procedure was followed for all subsequent

431 passages, with $\mathrm{P}_{\mathrm{N}}$ initiated by infecting $2.5 \times 10^{6} \mathrm{MT}-2$ cells with $\mathrm{P}_{\mathrm{N}-1}$ virus supernatant in

432 media containing the appropriate concentration of EFdA. Untreated cultures were also

433 initiated by infecting $2.5 \times 10^{6} \mathrm{MT}-2$ cells, in drug-free media, with $\mathrm{P}_{\mathrm{N}-1}$ virus. As infectivity

434 differences were expected between the $P_{0}$ virus and the output strains from each

435 passage, $\mathrm{P}_{2}$ and all subsequent passages were initiated by infecting cells with a p24

436 amount of $\mathrm{P}_{\mathrm{N}-1}$ virus equivalent to the $\mathrm{P}_{0}$ virus $\mathrm{p} 24$ content used to initiate $\mathrm{P}_{1}$. The

437 concentration of EFdA was doubled every two passages up to $\mathrm{P}_{6}$, after which point the

438 amount of drug was doubled every passage. Passages lasting more than 60 days without

439 syncytia formation were terminated and repeated, along with the previous passage. If no

440 syncytia were noted in a repeat passage after 30 days, the passage was terminated and

441 no further attempts were performed.

442 Dose response to individual mutants. All individual mutants were cloned into

443 NL4.3 using Emory's Cloning Core. After each virus was generated as stated above, 
444 TZM-GFP cells were plated at $1 \times 10^{3}$ cells/well in a 96-well plate and with serial-diluted

445 EFdA starting at $1 \mathrm{nM}$ and the cells and EFdA were incubated for $24 \mathrm{~h}$. After, the cells

446 were infected with virus and $1 \mu \mathrm{g} / \mathrm{mL}$ final concentration of DEAE Dextran and incubated

447 for 48 . The GFP positive cells were then counted using Cytation 5 (Biotek, Winooski, VT)

448 with Gen5.5 Software. EC50 curves were then determined using Prism 5 (GraphPad)

449 software.

450 Viral Replication Assays. JLTRG-R5 cells were plated at $5 \times 10^{6}$ cells/well in a

45112 well plate. The plasmid NL4.3 and various mutants were transfected into JLTRG-R5

452 cells with $1 \mu \mathrm{g}$ of viral DNA using Xtreme-GENE HP (Roche) Transfection reagent. After

$45348 \mathrm{~h}$ incubation, cells were imaged using Cytation 5 to quantify GFP sum signal, cells

454 were then split and media was replaced. Cells were subsequently imaged and split every

455 2-3 days until day 20. After day 20, genomic DNA was extracted using DNeasy Blood \&

456 Tissue Kit (Qiagen, Valencia, CA). Genomic DNA was PCR amplified using primers: 5'-

457 gaagaaatgaatttgccagg-3' and 5'-ctcatgttcttcttgggc-3' and Phusion DNA Polymerase

458 Master mix (New England Biolabs, Ipswich, MA). DNA was sent for Sanger Sequencing

459 to check for reversion mutations.

460 Specific Infectivity. TZM-GFP cells were plated at 10,000 cells/well in a 96-well

461 plate and incubated for $24 \mathrm{~h}$. After, cells were infected with the varying concentrations of

462 the virus and a $1 \mu \mathrm{g} / \mathrm{mL}$ final concentration of DEAE-dextran and incubated for $48 \mathrm{~h}$. The

463 GFP positive cells were then counted as described above. The p24 content of each virus

464 was also determined using an ELISA.

465 Steady State Kinetics and in vitro IC50s. HIV-1 RT and mutants were expressed 466 and purified as described previously (Bauman et al., 2008; Kirby et al., 2012; Michailidis 
467 et al., 2009; Ndongwe et al., 2012; Sarafianos et al., 2003; Schuckmann et al., 2010). RT

468 was expressed in JM-109 cells (Invitrogen) and purified by nickel affinity chromatography

469 and Mono $\mathrm{Q}$ anion exchange chromatography. Steady state kinetic parameters, $\mathrm{K}_{\mathrm{m}}$, for

470 incorporation of EFdA-MP were determined using plate-based assays measuring an 18

471 nucleotide primer annealed to 100 nucleotide DNA template (Kankanala et al., 2017;

472 Singh et al., 2012; Tang et al., 2019, 2017; Vernekar et al., 2017; Wang et al., 2018). The

473 reactions were carried out in $\mathrm{RT}$ buffer with $6 \mathrm{mM} \mathrm{MgCl}_{2}, 40 \mathrm{nM}$ Td100/Pd18, and $10 \mathrm{nM}$

$474 \mathrm{RT}$ in a final volume of $20 \mu \mathrm{l}$ for $30 \mathrm{~min}$ at $37^{\circ} \mathrm{C}$, and arrested by $100 \mathrm{mM}$ of EDTA. The

475 QuantiFluor dsDNA System (Promega) was used to quantify the amount of formed

476 double-stranded DNA. Reactions were read at ex/em 504/531 nm in a PerkinElmer

477 EnSpire Multilabel plate reader. $\mathrm{K}_{\mathrm{m}}$ were determined graphically using the Michaelis-

478 Menten equation using Prism Software.

479 Sequencing of passaged viruses. Viral RNA was purified from supernatants 480 using the QIAamp Viral RNA Mini kit (Qiagen, Valencia, CA), the concentration 481 determined with a Spectronic BioMate*3 UV spectrophotometer (Thermo Scientific, 482 Waltham, MA) and $500 \mathrm{ng}$ used as the template for cDNA synthesis. First-strand PCR 483 was performed using random hexamer primers and the SuperScript III First-Strand 484 Synthesis System for RT-PCR (Invitrogen, Carlsbad, CA). The resulting cDNA was PCR 485 amplified using HIV-1 LAl-specific primers ABR-RT-OF (1763 5'486 GGAGCCGATAGACAAGGAACTG-3') and ABR-RT-OR2 $\quad$ (3863 5'487 GGCTACTATTTCTTTTGCTACTACAGG-3'). These primers anneal to the 3' end of gag 488 and the 5' end of integrase, respectively, and generate a 2127 bp product spanning the 489 full length of the reverse transcriptase gene. PCR was performed using the Expand High 
490 Fidelity PCR System dNTPack (Roche Diagnostics GmbH, Mannheim, Germany), with

$4914.5 \mathrm{mM} \mathrm{MgCl}_{2}$ and $3.5 \mathrm{U}$ of enzyme mix used for each reaction. Reactions were run in a

492 PCR Sprint bench-top PCR cycler (Thermo Electron) with an initial denaturation of 3

493 minutes at $94^{\circ} \mathrm{C}$, followed by 30 amplification cycles, each consisting of 30 seconds at

$49494^{\circ} \mathrm{C}, 45$ seconds at $58^{\circ} \mathrm{C}$ and 150 seconds at $72{ }^{\circ} \mathrm{C}$. Following a seven-minute final

495 extension at $72^{\circ} \mathrm{C}$, samples were used immediately or stored at $-20^{\circ} \mathrm{C}$.

496 PCR products were separated by electrophoresis on a $1 \%$ agarose gel, and the

4972127 bp band harvested using the QIAquick Gel Extraction kit (Qiagen, Valencia, CA).

498 The concentration of DNA was determined by spectrophotometry, and 500 ng of sample

499 was submitted to ACGT Inc (Wheeling, IL) for full-length, double-stranded population

500 sequencing. The $\mathrm{P}_{0}$ consensus sequences from each virus were aligned in Clustal X-2

501 (Larkin et al., 2007) with an independent HIV-1 LAI nucleotide sequence (Accession

502 NC_001802) to ensure the stock viruses did not contain unexpected mutations.

503 Nucleotide consensus sequences from each passage were aligned to the appropriate $P_{0}$

504 consensus. Chromatograms were also inspected visually using Chromatogram Explorer

505 and DNABaser (Heracle BioSoft S.R.L., Pitesti, Romania) for the presence of

506 heterogeneous peaks and minority sequence populations not detectable in the consensus

507 sequence.

Clonal sequencing of full-length reverse transcriptase gene PCR products.

509 Approximately $105 \mathrm{ng}$ of full-length PCR product was ligated into the pGEM-T Vector

510 System (Promega, Madison, WI), at a 3:1 molar ratio of insert:vector and incubated

511 overnight at $4^{\circ} \mathrm{C}$. Ligations were transformed into MAX Efficiency DH5a competent cells

512 (Invitrogen, Carlsbad, CA) by heat shock. Blue-white screening was used to select clones 
513 with successful ligations, and plasmids containing the full-length reverse transcriptase

514 gene were isolated with the QIAprep Spin Miniprep kit (Qiagen, Valencia, CA). A minimum

515 of 20 clones from each sample were sequenced. Primers ABR-RT-OF and ABR-RT-OR2

516 were used to sequence the $5^{\prime}$ and $3^{\prime}$ ends of reverse transcriptase, while an internal

517 portion of the gene was sequenced with primer ABR-RT-IF (2211 5'-

518 CAGAGATGGAAAAGGAAGGG-3'). Clones were aligned with the appropriate $P_{0}$ stock

519 virus consensus in Clustal X-2, and the proportion of sequences with the novel

520 substitutions was determined.

521

\section{ACKNOWLEDGMENTS}

523 We acknowledge the key experimental contribution by Aaron B Reeve in the viral passage

524 experiments and also in the initial stages of writing a different version of the manuscript.

525 As he is inaccessible to approve this version of the manuscript, he is currently not included

526 in the author list, in compliance to the Journal's editorial guidelines. The author list will be

527 updated appropriately when he approves the submitted version. Michael Parniak was

528 involved in the early research and writing processes; as he is deceased it has not been

529 possible to obtain his approval of the final version of the manuscript.

530 This work was supported in whole or in part by NIH grants Al076119 to S.G.S.

531 T32GM008367 (provided training funds for M.E.C.).

532 The following reagents were obtained through the AIDS Research and Reference

533 Reagent Program, Division of AIDS, NIAID, NIH: MT-2 cells from Dr. Douglas Richman,

534 P4-R5 MAGI cells from Dr. Nathaniel Landau; HEK-293 cells from Dr. Andrew Rice. 
535 This study was supported in part by the Emory Integrated Genomics Core (EIGC), which

536 is subsidized by the Emory University School of Medicine and is one of the Emory

537 Integrated Core Facilities. Additional support was provided by the National Center for

538 Advancing Translational Sciences of the National Institutes of Health under Award

539 Number UL1TR000454. The content is solely the responsibility of the authors and does

540 not necessarily reflect the official views of the National Institutes of Health.

541 


\section{FIGURES}

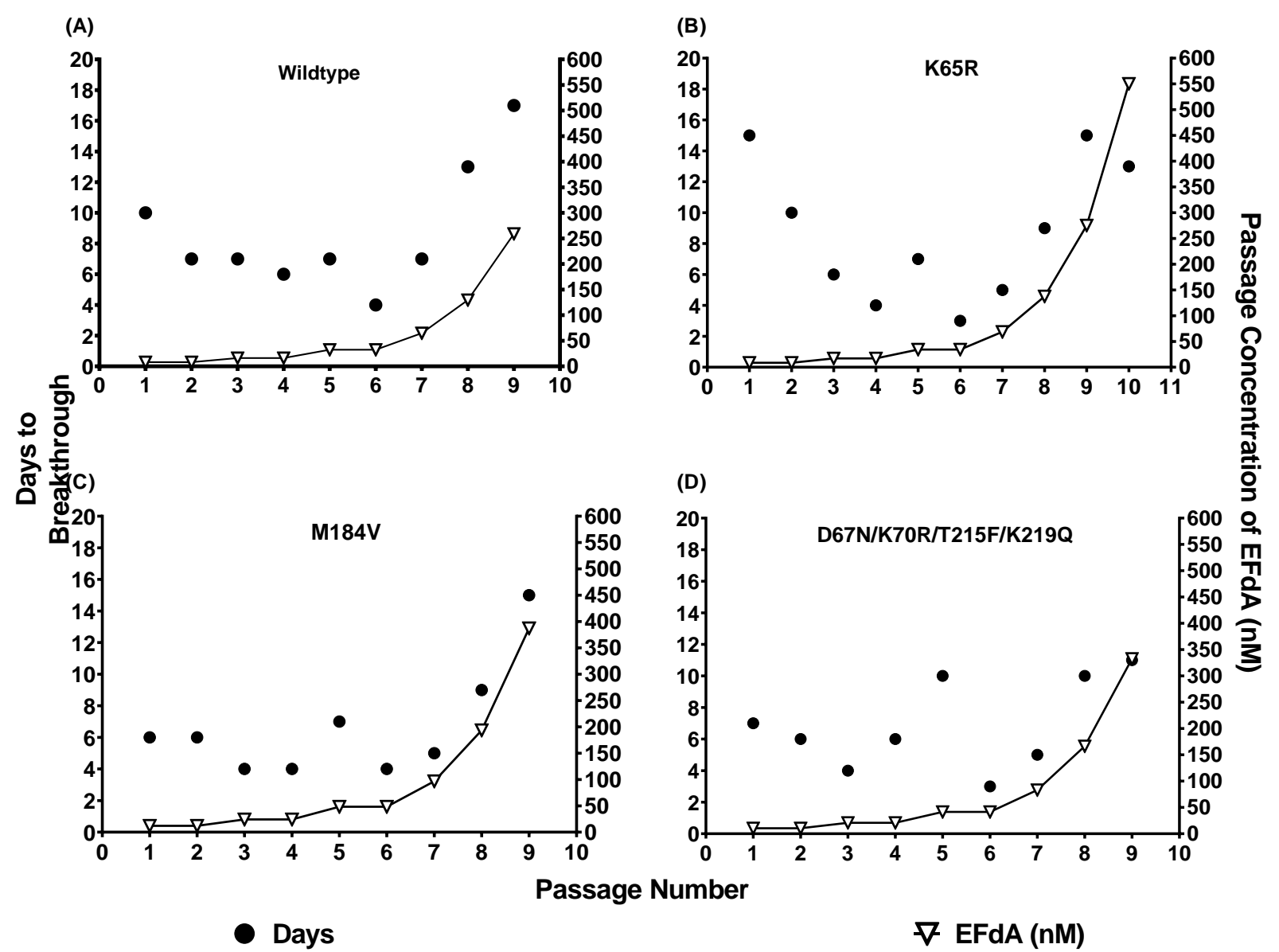

543 - Days

$\nabla$ EFdA (nM)

544 FIG. 1. Selection of resistance to EFdA by serial passage. MT-2 cells were infected with

545200 TCID $_{50}$ of HIV-1 in media supplemented with EFdA. Cells were split 1:10 every $2-3$

546 days and the supernatant replaced with fresh media supplemented with EFdA. Time to

547 breakthrough was determined as the number of days required for $\geq 75 \%$ syncytia

548 formation, at which point supernatants were harvested, assayed for p24 content and used

549 to infect the subsequent passage. EFdA concentration was doubled every second

550 passage until $P_{6}$, and every passage thereafter. Results represent a single trial for each

551 passage. Passages were initiated with (A) WT (xxLAI), (B) K65R, (C) M184V, and (D)

$552 \mathrm{D} 67 \mathrm{~N} / \mathrm{K} 70 \mathrm{R} / \mathrm{T} 215 \mathrm{~F} / \mathrm{K} 219 \mathrm{Q}$. 

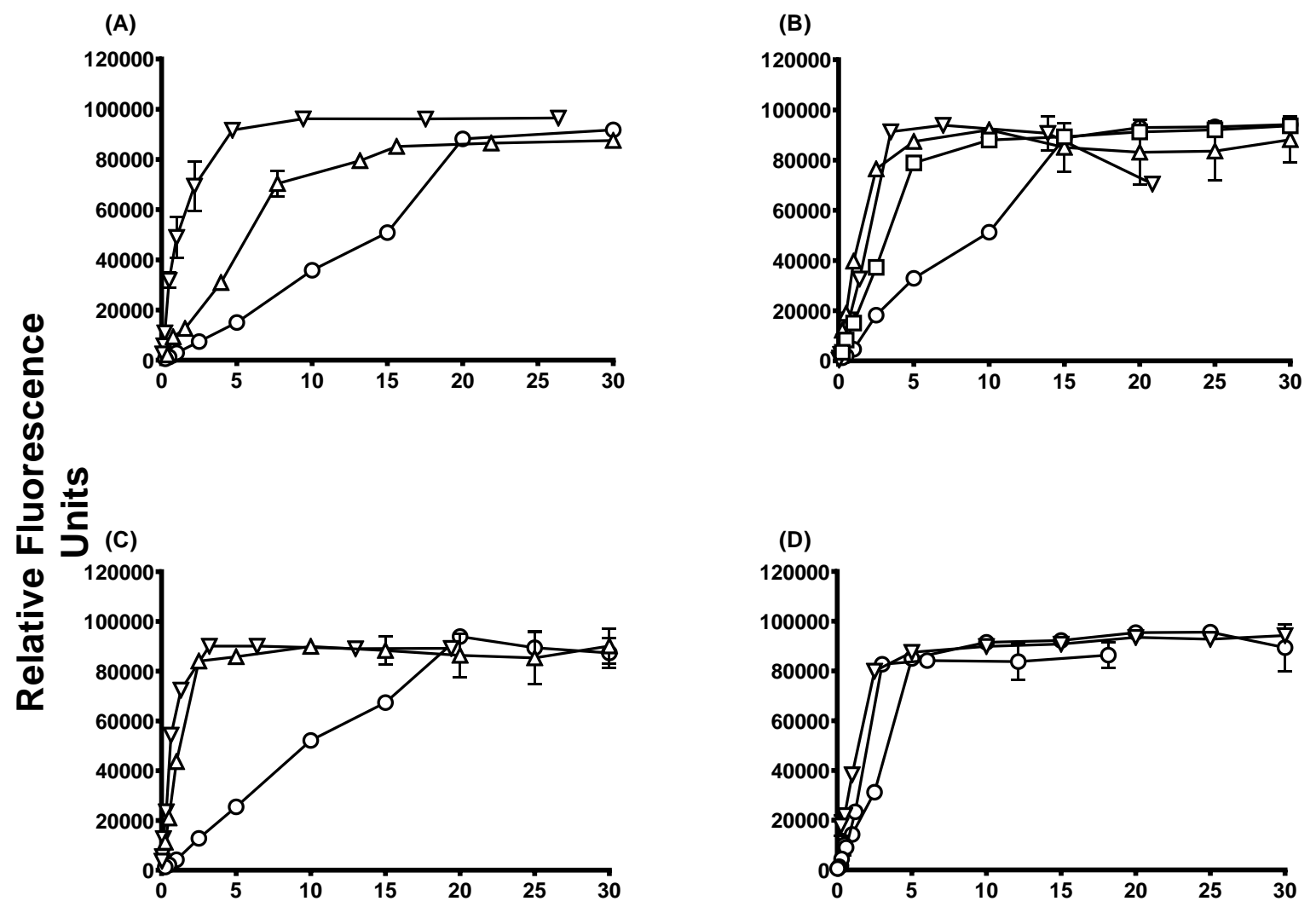

555 FIGURE 2. Infectivity of viruses selected during serial passage in EFdA. Untreated P4-

556 R5 MAGl cells were infected with virus supernatants from $\mathrm{P}_{0}, \mathrm{P}_{6}, \mathrm{P}_{9}$ or $\mathrm{P}_{10}$ (where

557 applicable). After $48 \mathrm{~h}$, cells were lysed and $\beta$-galactosidase activity assessed. Virus

558 infection is shown as relative fluorescence units. Results are the mean and S.D. of one

559 experiment with three replicates. (A) WT (xxLAI), (B) K65R, (C) M184V, and (D)

$560 \mathrm{D} 67 \mathrm{~N} / \mathrm{K} 70 \mathrm{R} / \mathrm{T} 215 \mathrm{~F} / \mathrm{K} 219 \mathrm{Q}$.

561

562

563

564 


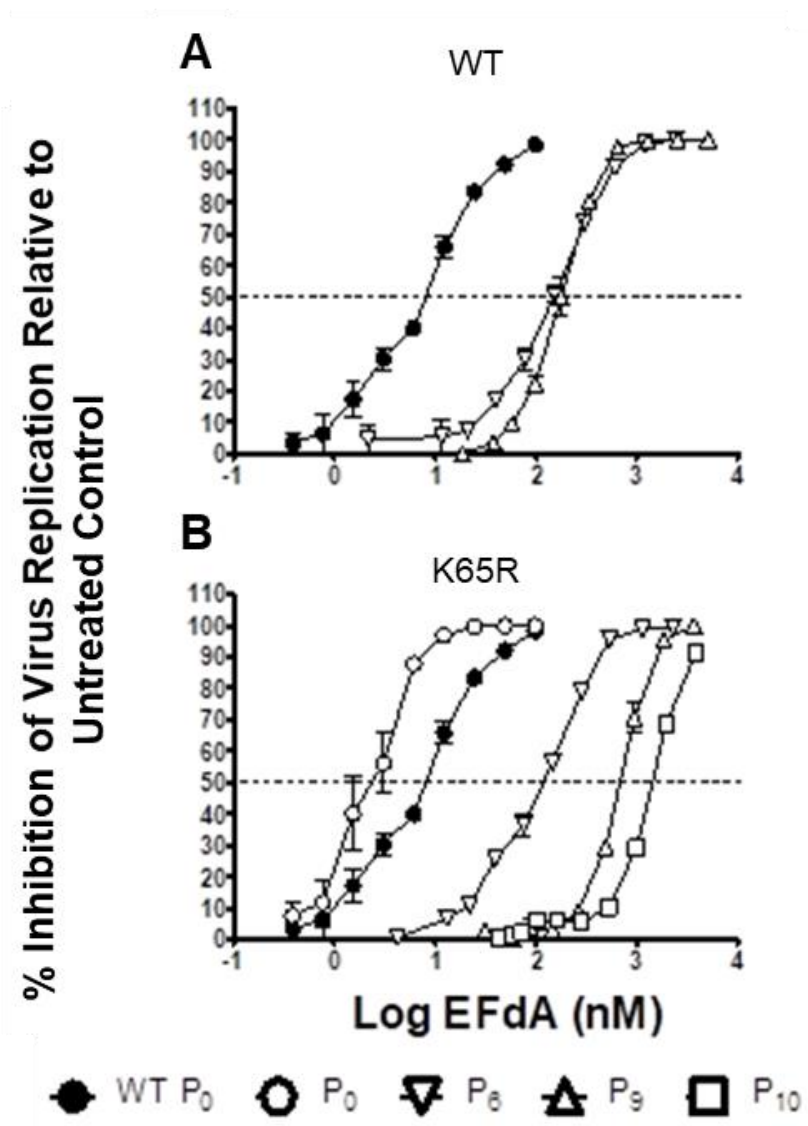

A
C

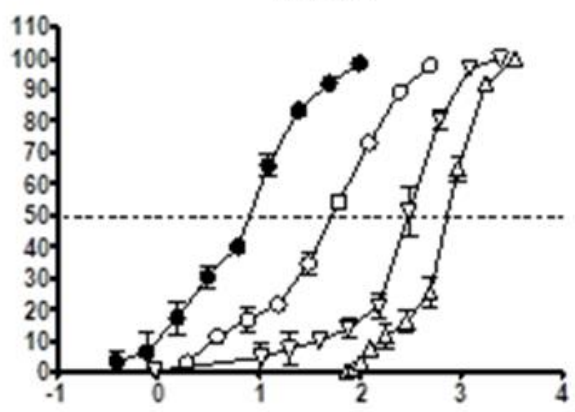

D $\mathrm{D} 67 \mathrm{~N} / \mathrm{K} 70 \mathrm{R} / \mathrm{T} 215 \mathrm{~F} / \mathrm{K} 219 \mathrm{Q}$

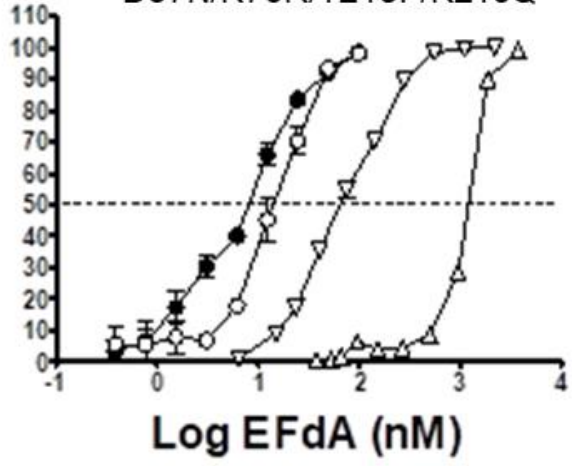

WT $P_{0}$

$0 P_{0} \quad \nabla P_{8}$

$\Delta P_{9} \quad \square P_{10}$

566 FIGURE 3. EFdA dose response for viruses selected during serial passage in EFdA. P4-

567 R5 MAGI cells were infected with virus supernatants from $P_{0}, P_{6}, P_{9}$ or $P_{10}$ (where

568 applicable) and treated with EFdA. Following incubation for $48 \mathrm{~h}$, cells were lysed and $\beta$ -

569 galactosidase activity assessed. (A, B, C, D) Inhibition of virus replication relative to

570 infected untreated cells. Dashed line represents $50 \%$ inhibition of viral replication.

571 Results are the mean and S.D. of one experiment with three replicates. 


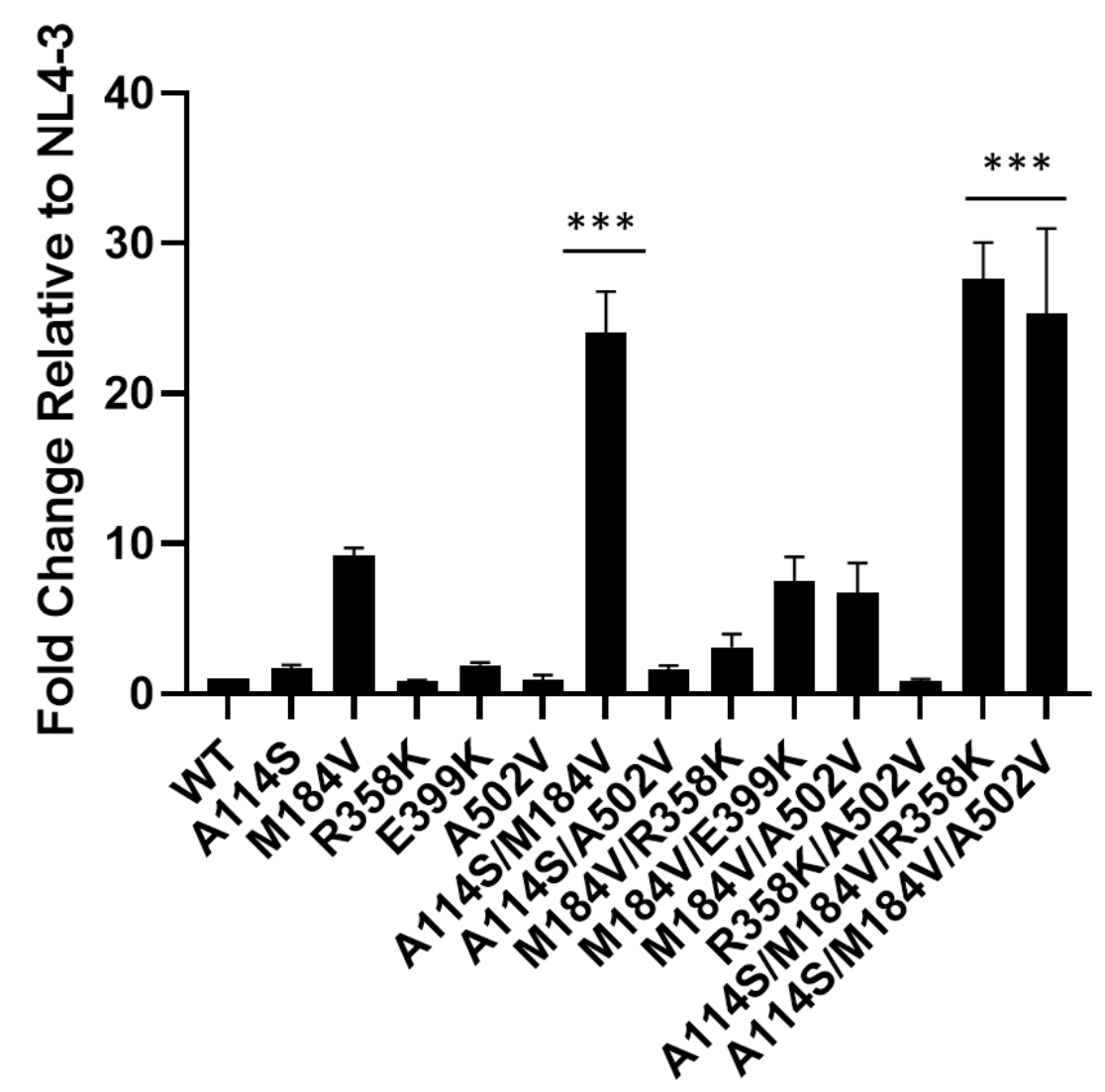

573 FIGURE 4. Fold-change EC $_{50}$ S relative to NL4-3. TZM-GFP cells were pre-treated with

574 EFdA and infected after 24h. GFP positive cells (infected cells) were counted in varying

575 concentrations of EFdA. Mutants were normalized to WT infection to produce fold change.

576 EFdA dose response curves were produced for each mutant and the $\mathrm{EC}_{50}$ s calculated.

$577^{* * *}=\mathrm{p}<.0001$ Statistical significance was determined using a one-way ANOVA with

578 Tukey's post-test. Results are the mean and S.D. of four experiments with duplicates. 


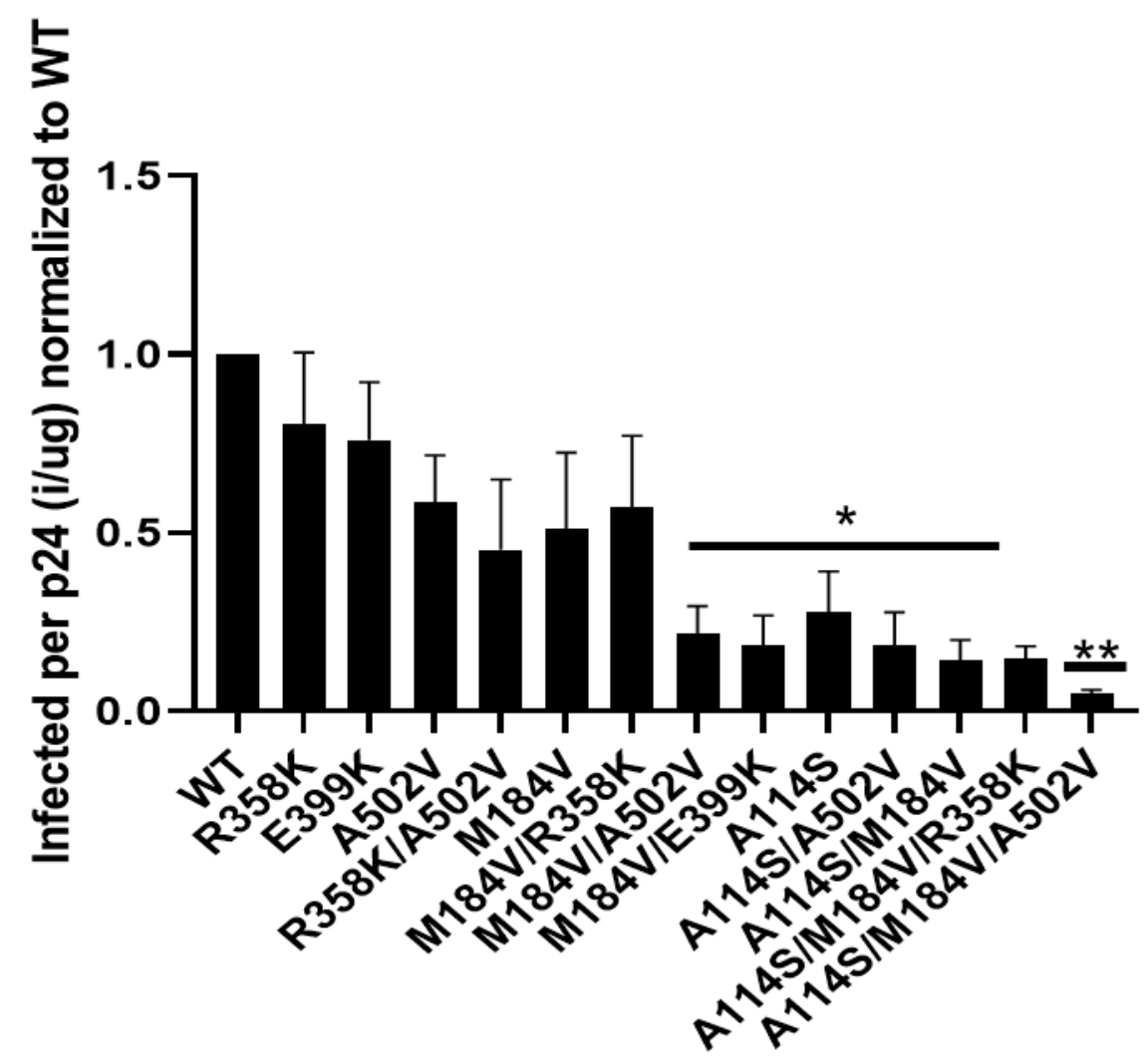

\section{EFdA Passaging Mutants}

580 FIGURE 5. Single-round replication assays using TZM-GFP cells infected with individual

581 mutants. An ELISA was also performed on the virus to determine amount of p24 (total

582 virus in medium). The ratio of infected cells per p24 was then calculated and normalized

583 to WT. Statistical significance was determined using a one-way ANOVA with Dunnet's 584 multiple comparison test $\left({ }^{*}=p<.05,{ }^{* *}=p<.01\right)$. Results are the mean and S.D. of four 585 experiments in triplicates. 
587 Table 1. Amino acid mutations in WT-, K65R-, M184V- and D67N/K70R/T215F/K219Q-derived viruses

588 during serial passage in progressively increasing concentrations of EFdA

\begin{tabular}{|c|c|c|c|}
\hline \multirow[t]{2}{*}{ Virus } & \multirow[t]{2}{*}{ Passage } & \multicolumn{2}{|l|}{ Sequencing $^{\mathrm{a}}$} \\
\hline & & Amino Acid Mutations $^{\mathrm{b}}$ & $\begin{array}{l}\text { Proportion of } \\
\text { Sequence } \\
\text { Population (\%) }\end{array}$ \\
\hline \multirow{6}{*}{$\begin{array}{l}\text { WT } \\
(x x L A I)\end{array}$} & $0^{c}$ & None & 100 \\
\hline & 6 & M184I & 100 \\
\hline & 9 & M184I & 36.4 \\
\hline & & M184I, E399K & 31.8 \\
\hline & & M184V & 18.2 \\
\hline & & None & 13.6 \\
\hline \multirow[t]{10}{*}{ K65R } & $0^{c}$ & None & 100 \\
\hline & 6 & R65K, M184I & 90.9 \\
\hline & & R65K, M184V & 9.1 \\
\hline & 9 & R65K, M184V, A502V & 43.5 \\
\hline & & R65K, M184I & 34.8 \\
\hline & & $\mathrm{R} 65 \mathrm{~K}, \mathrm{M} 184 \mathrm{~V}$ & 17.4 \\
\hline & & R65K, M184I, A502V & 4.3 \\
\hline & 10 & R65K, A114S, M184V, A502V & 90.9 \\
\hline & & R65K, A114S, M184V & 4.5 \\
\hline & & R65K, A114S, A502V & 4.5 \\
\hline \multirow[t]{7}{*}{ M184V } & $0^{c}$ & None & 100 \\
\hline & 6 & R358K & 45 \\
\hline & & None & 55 \\
\hline & 9 & R358K & 90.5 \\
\hline & & None & 9.5 \\
\hline & 10 & R358K & 72.7 \\
\hline & & $\mathrm{R} 358 \mathrm{~K} / \mathrm{A} 502 \mathrm{~V}$ & 27.3 \\
\hline \multirow{6}{*}{$\begin{array}{l}\text { D67N/ } \\
\text { K70R/ } \\
\text { T215F/ } \\
\text { K219Q }\end{array}$} & $0^{c}$ & None & 100 \\
\hline & & & \\
\hline & 6 & M184V & 66.7 \\
\hline & & None & 33.3 \\
\hline & 9 & M184V & 18.2 \\
\hline & & M184V, E399K & 81.8 \\
\hline
\end{tabular}

589 apopulation and clonal sequencing of viral RNA from passage supernatants was performed as described

590 in Materials and Methods.

591 bRelative to unpassaged stock virus of the appropriate strain

592 cUnpassaged stock virus 
bioRxiv preprint doi: https://doi.org/10.1101/2020.09.04.281485; this version posted September 4, 2020. The copyright holder for this preprint (which was not certified by peer review) is the author/funder. All rights reserved. No reuse allowed without permission.

593

Table 2. Steady-State Kinetics for Reverse Transcriptase Mutants

\begin{tabular}{|l|l|l|l|l|l|l|l|l|}
\hline & WT RT & A114S & M184V & R358K & E399K & A502V & 184V/358K/502V & $\mathbf{1 1 4 S} / \mathbf{1 8 4 V} / \mathbf{5 0 2 V}$ \\
\hline $\mathrm{K}_{\mathrm{m}}(\mathrm{nM})$ & 1448 & 2758 & 1791 & 2008 & 1795 & 1110 & 2327 & 6659 \\
\hline Fold Change $\mathrm{K}_{\mathrm{m}}$ & 1 & 1.9 & 1.2 & 1.4 & 1.2 & 0.8 & 1.6 & 4.6 \\
\hline Fold Change $\mathrm{k}_{\mathrm{cat}} / \mathrm{K}_{\mathrm{m}}$ & 1 & 2.1 & 1.2 & 1.4 & 1.2 & 1 & 1.3 & 6.5 \\
\hline
\end{tabular}

594 
Arion, D., Sluis-Cremer, N., Parniak, M.A., 2000. Mechanism by which phosphonoformic acid resistance mutations restore 3'- azido-3'-deoxythymidine (AZT) sensitivity to AZT-resistant HIV-1 reverse transcriptase. J. Biol. Chem. 275, 9251-9255. https://doi.org/10.1074/jbc.275.13.9251

601

602

603

604

Barrett, S.E., Teller, R.S., Forster, S.P., Li, L., Mackey, M.A., Skomski, D., Yang, Z., Fillgrove, K.L., Doto, G.J., Wood, S.L., Lebron, J., Grobler, J.A., Sanchez, R.I., Liu, Z., Lu, B., Niu, T., Sun, L., Gindy, M.E., 2018. Extended-duration MK-8591-eluting implant as a candidate for HIV treatment and prevention. Antimicrob. Agents Chemother. https://doi.org/10.1128/AAC.01058-18

Bauman, J.D., Das, K., Ho, W.C., Baweja, M., Himmel, D.M., Clark, A.D., Oren, D.A., Boyer, P.L., Hughes, S.H., Shatkin, A.J., Arnold, E., 2008. Crystal engineering of HIV-1 reverse transcriptase for structure-based drug design. Nucleic Acids Res. https://doi.org/10.1093/nar/gkn464

Bazmi, H.Z., Hammond, J.L., Cavalcanti, S.C., Chu, C.K., Schinazi, R.F., Mellors, J.W., 2000. In vitro selection of mutations in the human immunodeficiency virus type 1 reverse transcriptase that decrease susceptibility to (-)-beta-D-dioxolane-guanosine and suppress resistance to 3'-azido-3'-deoxythymidine. Antimicrob. Agents Chemother. 44, 1783-8.

Boucher, C.A., Cammack, N., Schipper, P., Schuurman, R., Rouse, P., Wainberg, M.A., Cameron, J.M., 1993. High-level resistance to (-) enantiomeric 2'-deoxy-3'thiacytidine in vitro is due to one amino acid substitution in the catalytic site of human immunodeficiency virus type 1 reverse transcriptase. Antimicrob. Agents Chemother. 37, 2231-2234. https://doi.org/10.1128/AAC.37.10.2231

Boufford, D.E., Spongberg, S.A., 1983. Eastern Asian-Eastern North American Phytogeographical Relationships-A History From the Time of Linnaeus to the Twentieth Century. Ann. Missouri Bot. Gard. 70, 423-439. https://doi.org/10.2307/2992081

Boyer, P.L., Sarafianos, S.G., Arnold, E., Hughes, S.H., 2002. The M184V Mutation Reduces the Selective Excision of Zidovudine 5'-Monophosphate (AZTMP) by the Reverse Transcriptase of Human Immunodeficiency Virus Type 1. J. Virol. 76, 3248-3256. https://doi.org/10.1128/JVI.76.7.3248-3256.2002

Brehm, J.H., Koontz, D., Meteer, J.D., Pathak, V., Sluis-Cremer, N., Mellors, J.W., 2007. Selection of Mutations in the Connection and RNase H Domains of Human Immunodeficiency Virus Type 1 Reverse Transcriptase That Increase Resistance to 3'-Azido-3'-Dideoxythymidine. J. Virol. 81, 7852-7859. https://doi.org/10.1128/JVI.02203-06

Brenner, B.G., Coutsinos, D., 2009. The K65R mutation in HIV-1 reverse transcriptase: Genetic barriers, resistance profile and clinical implications. HIV Ther. 3, 583-594. https://doi.org/10.2217/hiv.09.40

Brinkman, K., Kakuda, T.N., 2000. Mitochondrial Toxicity of Nucleoside Analogue Reverse Transcriptase Inhibitors: A Looming Obstacle for Long-term Antiretroviral 

https://doi.org/10.1887/0750303468/b293c2

Brinkman, K., Smeitink, J.A., Romijn, J.A., Reiss, P., 1999. Mitochondrial toxicity induced by nucleoside-analogue reverse-transcriptase inhibitors is a key factor in the pathogenesis of antiretroviral-therapy-related lipodystrophy. Lancet 354, 11121115. https://doi.org/10.1016/S0140-6736(99)06102-4

Brinkman, K., ter Hofstede, H.J.M., Burger, D.M., Smeitink, J.A.M., Koopmans, P.P., 1998. Adverse effects of reverse transcriptase inhibitors. Aids 12, 1735-1744. https://doi.org/10.1097/00002030-199814000-00004

Cases-Gonzalez, C.E., Menéndez-Arias, L., 2005. Nucleotide specificity of HIV-1 reverse transcriptases with amino acid substitutions affecting Ala-114. Biochem. J. 387, 221-229. https://doi.org/10.1042/BJ20041056

Charneau, P., Mirambeau, G., Roux, P., Paulous, S., Buc, H., Clavel, F., 1994. HIV-1 reverse transcription. A termination step at the center of the genome. J. Mol. Biol. 241, 651-662. https://doi.org/10.1006/jmbi.1994.1542

Chiang, C.C., Tseng, Y.T., Huang, K.J., Pan, Y.Y., Wang, C.T., 2012. Mutations in the HIV-1 reverse transcriptase tryptophan repeat motif affect virion maturation and Gag-Pol packaging. Virology 422, 278-287. https://doi.org/10.1016/j.virol.2011.11.001

Cihlar, T., Fordyce, M., 2016. Current status and prospects of HIV treatment. Curr. Opin. Virol. 18, 50-56. https://doi.org/10.1016/j.coviro.2016.03.004

Clutter, D.S., Jordan, M.R., Bertagnolio, S., Shafer, R.W., 2016. HIV-1 drug resistance and resistance testing. Infect. Genet. Evol. https://doi.org/10.1016/j.meegid.2016.08.031

Delviks-Frankenberry, K.A., Nikolenko, G.N., Boyer, P.L., Hughes, S.H., Coffin, J.M., Jere, A., Pathak, V.K., 2008. HIV-1 reverse transcriptase connection subdomain mutations reduce template RNA degradation and enhance AZT excision. Proc. Natl. Acad. Sci. 105, 10943-10948. https://doi.org/10.1073/pnas.0804660105

Derdeyn, C.A., Decker, J.M., Sfakianos, J.N., Wu, X., O’Brien, W.A., Ratner, L., Kappes, J.C., Shaw, G.M., Hunter, E., 2000. Sensitivity of Human Immunodeficiency Virus Type 1 to the Fusion Inhibitor T-20 Is Modulated by Coreceptor Specificity Defined by the V3 Loop of gp120. J. Virol. https://doi.org/10.1128/jvi.74.18.8358-8367.2000

Ding, J., Das, K., Hsiou, Y., Sarafianos, S.G., Clark, A.D., Jacobo-Molina, A., Tantillo, C., Hughes, S.H., Arnold, E., 1998. Structure and functional implications of the polymerase active site region in a complex of HIV-1 RT with a double-stranded DNA template-primer and an antibody Fab fragment at $2.8 \AA$ resolution. J. Mol. Biol. 284, 1095-1111. https://doi.org/10.1006/jmbi.1998.2208

Eggleton, J.S., Nagalli, S., 2020. Highly Active Antiretroviral Therapy (HAART). StatPearls [Internet], Treasure Island (FL). 
677 Frost, S.D.W., Nijhuis, M., Schuurman, R., Boucher, C.A.B., Brown, A.J.L., 2000.

678

679

680

681

682

683

684

685

686

687

688

689

690

691

692

693

694

695

696

697

698

699

700

701

702

703

704

705

706

707

708

709

710

711

712

713

714

715

716

717 Infected Individuals: the Relative Roles of Drift and Selection. J. Virol. 74, 62626268. https://doi.org/10.1128/JVI.74.14.6262-6268.2000

Gallois-Montbrun, S., Schneider, B., Chen, Y., Giacomoni-Fernandes, V., Mulard, L., Morera, S., Janin, J., Deville-Bonne, D., Veron, M., 2002. Improving nucleoside diphosphate kinase for antiviral nucleotide analogs activation. J. Biol. Chem. 277, 39953-39959. https://doi.org/10.1074/jbc.M206360200

Graham, F.L., Smiley, J., Russell, W.C., Nairn, R., 1977. Characteristics of a human cell line transformed by DNA from human adenovirus type 5. J. Gen. Virol. 36, 59-72. https://doi.org/10.1099/0022-1317-36-1-59

Grobler, J.A., Fillgrove, K., Hazuda, D., Huang, Q., Lai, M.T., Matthews, R.P., Rudd, D.J., Vargo, R., 2019. MK-8591 potency and PK provide high inhibitory quotients at low doses QD and QW, in: Conference on Retroviruses and Opportunistic Infections (CROI).

Haertle, T., Carrera, C.J., Wasson, D.B., Sowers, L.C., Richman, D.D., Carson, D.A., 1988. Metabolism and anti-human immunodeficiency virus-1 activity of 2-halo-2',3'dideoxyadenosine derivatives. J. Biol. Chem. 263, 5870-5875.

Harris, D., Kaushik, N., Pandey, P.K., Yadav, P.N.S., Pandey, V.N., 1998. Functional Analysis of Amino Acid Residues Constituting the dNTP Binding Pocket of HIV-1 Reverse Transcriptase. J. Biol. Chem. 273, 33624-33634. https://doi.org/10.1074/jbc.273.50.33624

Hattori, S., Ide, K., Nakata, H., Harada, H., Suzu, S., Ashida, N., Kohgo, S., Hayakawa, H., Mitsuya, H., Okada, S., 2009. Potent Activity of a Nucleoside Reverse Transcriptase Inhibitor, 4'-Ethynyl-2-Fluoro-2'-Deoxyadenosine, against Human Immunodeficiency Virus Type 1 Infection in a Model Using Human Peripheral Blood Mononuclear Cell-Transplanted NOD/SCID Janus Kinase 3 Kno. Antimicrob. Agents Chemother. 53, 3887-3893. https://doi.org/10.1128/AAC.00270-09

Huang, H., Chopra, R., Verdine, G.L., Harrison, S.C., 1998. Structure of a covalently trapped catalytic complex of HIV-1 reverse transcriptase: Implications for drug resistance. Science (80-. ). 282, 1669-1675.

https://doi.org/10.1126/science.282.5394.1669

J., G., C., M., C., F., D., D., L., S., M., V., S., B., K., F., D., H., 2017. MK-8591 concentrations at sites of HIV transmission and replication. Top. Antivir. Med.

J., G., E., F., S.E., B., S.L., W., W., A., K.L., F., M.-T., L., M., G., M., I., 2016. Longacting oral and parenteral dosing of MK-8591 for HIV treatment or prophylaxis. Top. Antivir. Med.

Julias, J.G., McWilliams, M.J., Sarafianos, S.G., Alvord, W.G., Arnold, E., Hughes, S.H., 2003. Mutation of amino acids in the connection domain of human immunodeficiency virus type 1 reverse transcriptase that contact the templateprimer affects RNase H activity. J. Virol. 77, 8548-8554. 
Kageyama, M., Nagasawa, T., Yoshida, M., Ohrui, H., Kuwahara, S., 2011. Enantioselective total synthesis of the potent Anti-HIV nucleoside EFdA. Org. Lett. 13, 5264-5266. https://doi.org/10.1021/ol202116k

Kankanala, J., Kirby, K.A., Huber, A.D., Casey, M.C., Wilson, D.J., Sarafianos, S.G., Wang, Z., 2017. Design, synthesis and biological evaluations of N-Hydroxy thienopyrimidine-2,4-diones as inhibitors of HIV reverse transcriptase-associated

724

725

Kawamoto, A., Kodama, E., Sarafianos, S.G., Sakagami, Y., Kohgo, S., Kitano, K., Ashida, N., Iwai, Y., Hayakawa, H., Nakata, H., Mitsuya, H., Arnold, E., Matsuoka, M., 2008a. 2'-Deoxy-4'-C-ethynyl-2-halo-adenosines active against drug-resistant human immunodeficiency virus type 1 variants. Int. J. Biochem. Cell Biol. 40, 24102420. https://doi.org/10.1016/j.biocel.2008.04.007

Kawamoto, A., Kodama, E., Sarafianos, S.G., Sakagami, Y., Kohgo, S., Kitano, K., Ashida, N., Iwai, Y., Hayakawa, H., Nakata, H., Mitsuya, H., Arnold, E., Matsuoka, M., 2008b. 2'-Deoxy-4'-C-ethynyl-2-halo-adenosines active against drug-resistant human immunodeficiency virus type 1 variants. Int. J. Biochem. Cell Biol. https://doi.org/10.1016/j.biocel.2008.04.007

Kellam, P., Boucher, C.A., Larder, B.A., 1992. Fifth mutation in human immunodeficiency virus type 1 reverse transcriptase contributes to the development of high-level resistance to zidovudine. Proc. Natl. Acad. Sci. 89, 1934-1938. https://doi.org/10.1073/pnas.89.5.1934

Keulen, W., Back, N.K., van Wijk, a, Boucher, C. a, Berkhout, B., 1997. Initial appearance of the 184lle variant in lamivudine-treated patients is caused by the mutational bias of human immunodeficiency virus type 1 reverse transcriptase. J. Virol. 71, 3346-50.

Kirby, K.A., Marchand, B., Ong, Y.T., Ndongwe, T.P., Hachiya, A., Michailidis, E., Leslie, M.D., Sietsema, D. V., Fetterly, T.L., Dorst, C.A., Singh, K., Wang, Z., Parniak, M.A., Sarafianos, S.G., 2012. Structural and inhibition studies of the $\mathrm{RNase} \mathrm{H}$ function of xenotropic murine leukemia virus-related virus reverse transcriptase. Antimicrob. Agents Chemother. https://doi.org/10.1128/AAC.0600011

Kirby, K.A., Michailidis, E., Fetterly, T.L., Steinbach, M.A., Singh, K., Marchand, B., Leslie, M.D., Hagedorn, A.N., Kodama, E.N., Marquez, V.E., Hughes, S.H., Mitsuya, H., Parniak, M.A., Sarafianos, S.G., 2013. Effects of substitutions at the 4' and 2 positions on the bioactivity of 4'-ethynyl-2-fluoro-2'-deoxyadenosine. Antimicrob. Agents Chemother. 57, 6254-6264. https://doi.org/10.1128/AAC.01703-13

Kirby, K.A., Singh, K., Michailidis, E., Marchand, B., Kodama, E.N., Ashida, N., Mitsuya, H., Parniak, M.A., Sarafianos, S.G., 2011. The sugar ring conformation of 4'ethynyl-2-fluoro-2'-deoxyadenosine and its recognition by the polymerase active site of HIV reverse transcriptase. Cell. Mol. Biol. https://doi.org/10.1170/T900 
Kodama, E.I., Kohgo, S., Kitano, K., Machida, H., Gatanaga, H., Shigeta, S., Matsuoka, M., Ohrui, H., Mitsuya, H., 2001. 4'-Ethynyl nucleoside analogs: Potent inhibitors of multidrug-resistant human immunodeficiency virus variants in vitro. Antimicrob. Agents Chemother. 45, 1539-1546. https://doi.org/10.1128/AAC.45.5.15391546.2001

Kutsch, O., Levy, D.N., Bates, P.J., Decker, J., Kosloff, B.R., Shaw, G.M., Priebe, W., Benveniste, E.N., 2004. Bis-Anthracycline Antibiotics Inhibit Human Immunodeficiency Virus Type 1 Transcription. Antimicrob. Agents Chemother. https://doi.org/10.1128/AAC.48.5.1652-1663.2004

Larder, B.A., Kemp, S.D., 1989. Multiple mutations in HIV-1 reverse transcriptase confer high-level resistance to zidovudine (AZT). Science (80-. ). 246, 1155-1158. https://doi.org/10.1126/science.2479983

Larder, B.A., Kemp, S.D., Harrigan, P.R., 1995. Potential mechanism for sustained antiretroviral efficacy of AZT-3TC combination therapy. Science (80-. ). 269, 696699. https://doi.org/10.1126/science.7542804

Larder, B.A., Kemp, S.D., Purifoy, D.J., 2006. Infectious potential of human immunodeficiency virus type 1 reverse transcriptase mutants with altered inhibitor sensitivity. Proc. Natl. Acad. Sci. 86, 4803-4807. https://doi.org/10.1073/pnas.86.13.4803

Larder, B.A., Purifoy, D.J.M., Powell, K.L., Darby, G., 1987. Site-specific mutagenesis of AIDS virus reverse transcriptase. Nature 327, 716-717. https://doi.org/10.1038/327716a0

Larkin, M.A., Blackshields, G., Brown, N.P., Chenna, R., McGettigan, P.A., McWilliams, H., Valentin, F., Wallace, I.M., Wilm, A., Lopez, R., Thompson, J.D., Gibson, T.J., Higgins, D.G., 2007. Clustal W and ClustalX version 2. Bioinformatics 23, 29472948.

Lengruber, R.B., Delviks-Frankenberry, K.A., Nikolenko, G.N., Baumann, J., Santos, A.F., Pathak, V.K., Soares, M.A., 2011. Phenotypic characterization of drug resistance-associated mutations in HIV-1 RT connection and RNase $\mathrm{H}$ domains and their correlation with thymidine analogue mutations. J. Antimicrob. Chemother. 66, 702-708. https://doi.org/10.1093/jac/dkr005

Lewis, W., Day, B.J., Copeland, W.C., 2003. Mitochondrial toxicity of NRTI antiviral drugs: An integrated cellular perspective. Nat. Rev. Drug Discov. 2, 812-822. https://doi.org/10.1038/nrd1201

Little, S.J., Holte, S., Routy, J.-P., Daar, E.S., Markowitz, M., Collier, A.C., Koup, R.A., Mellors, J.W., Connick, E., Conway, B., Kilby, M., Wang, L., Whitcomb, J.M., Hellmann, N.S., Richman, D.D., 2002. Antiretroviral-Drug Resistance among Patients Recently Infected with HIV. N. Engl. J. Med. 347, 385-394. https://doi.org/10.1056/NEJMoa013552

Maeda, K., Desai, D. V., Aoki, M., Nakata, H., Kodama, E.N., Mitsuya, H., 2014. Delayed emergence of HIV-1 variants resistant to 4'-ethynyl-2-fluoro-2'- 
801

802

803

804

805

806

807

808

809

810

811

812

813

814

815

816

817

818

819

820

821

822

823

824

825

826

827

828

829

830

831

832

833

834

835

836

837

838

839

840

841

deoxyadenosine: Comparative sequential passage study with lamivudine, tenofovir, emtricitabine and BMS-986001. Antivir. Ther. 19, 179-189.

https://doi.org/10.3851/IMP2697

Mahy, M., Marsh, K., Sabin, K., Wanyeki, I., Daher, J., Ghys, P.D., 2019. HIV estimates through 2018: Data for decision-making. AIDS. https://doi.org/10.1097/QAD.0000000000002321

Margolis, D.A., Boffito, M., 2015. Long-acting antiviral agents for HIV treatment. Curr. Opin. HIV AIDS 10, 246-252. https://doi.org/10.1097/COH.0000000000000169

Margot, N.A., Isaacson, E., McGowan, I., Cheng, A.K., Schooley, R.T., Miller, M.D., 2002. Genotypic and phenotypic analyses of HIV-1 in antiretroviral-experienced patients treated with tenofovir DF. Aids 16, 1227-1235. https://doi.org/10.1097/00002030-200206140-00004

Markowitz, M., Gettie, A., St Bernard, L., Andrews, C.D., Mohri, H., Horowitz, A., Grasperge, B.F., Blanchard, J.L., Niu, T., Sun, L., Fillgrove, K., Hazuda, D.J., Grobler, J.A., 2020. Once-Weekly Oral Dosing of MK-8591 Protects Male Rhesus Macaques from Intrarectal Challenge with SHIV109CP3. J. Infect. Dis. https://doi.org/10.1093/infdis/jiz271

Markowitz, M., Sarafianos, S.G., 2018. 4'-Ethynyl-2-fluoro-2'-deoxyadenosine, MK8591: A novel HIV-1 reverse transcriptase translocation inhibitor. Curr. Opin. HIV AIDS. https://doi.org/10.1097/COH.0000000000000467

Menéndez-Arias, L., 2008. Mechanisms of resistance to nucleoside analogue inhibitors of HIV-1 reverse transcriptase. Virus Res. 134, 124-146.

https://doi.org/10.1016/j.virusres.2007.12.015

Merluzzi, V.J., Hargrave, K.D., Labadia, M., Grozinger, K., Skoog, M., Wu, J.C., ChengKon, S., Eckner, K., Hattox, S., Adams, J., Rosehthal, A.S., Faanes, R., Eckner, R.J., Koup, R.A., Sullivan, J.L., Sarafianos, S.G., Marchand, B., Das, K., Himmel, D., Michael, A., Hughes, S.H., Arnold, E., 2010. Structure and Function oh HIV-1 Reverse Transcriptase: Molecular Mechanisms of Polymerization and Inhibition. Science (80-. ). 250, 1411-1413. https://doi.org/10.1016/j.jmb.2008.10.071.Structure

Michailidis, E., Huber, A.D., Ryan, E.M., Ong, Y.T., Leslie, M.D., Matzek, K.B., Singh, K., Marchand, B., Hagedorn, A.N., Kirby, K.A., Rohan, L.C., Kodama, E.N., Mitsuya, H., Parniak, M.A., Sarafianosa, S.G., 2014a. 4'-Ethynyl-2-fluoro-2'deoxyadenosine $(E F d A)$ inhibits HIV-1 reverse transcriptase with multiple mechanisms. J. Biol. Chem. https://doi.org/10.1074/jbc.M114.562694

Michailidis, E., Huber, A.D., Ryan, E.M., Ong, Y.T., Leslie, M.D., Matzek, K.B., Singh, K., Marchand, B., Hagedorn, A.N., Kirby, K.A., Rohan, L.C., Kodama, E.N., Mitsuya, H., Parniak, M.A., Sarafianosa, S.G., 2014b. 4'-Ethynyl-2-fluoro-2'deoxyadenosine (EFdA) inhibits HIV-1 reverse transcriptase with multiple mechanisms. J. Biol. Chem. 289, 24533-24548.

https://doi.org/10.1074/jbc.M114.562694 
842

843

844

845

846

847

848

849

850

851

852

853

854

855

856

857

858

859

860

861

862

863

864

865

866

867

868

869

870

871

872

873

874

875

876

877

878

879

880

881

882

883

Michailidis, E., Marchand, B., Kodama, E.N., Singh, K., Matsuoka, M., Kirby, K.A., Ryan, E.M., Sawani, A.M., Nagy, E., Ashida, N., Mitsuya, H., Parniak, M.A., Sarafianos, S.G., 2009. Mechanism of inhibition of HIV-1 reverse transcriptase by 4'-ethynyl-2-fluoro-2'-deoxyadenosine triphosphate, a translocation-defective reverse transcriptase inhibitor. J. Biol. Chem. 284, 35681-35691. https://doi.org/10.1074/jbc.M109.036616

Michailidis, E., Ryan, E.M., Hachiya, A., Kirby, K.A., Marchand, B., Leslie, M.D., Huber, A.D., Ong, Y.T., Jackson, J.C., Singh, K., Kodama, E.N., Mitsuya, H., Parniak, M.A., Sarafianos, S.G., 2013. Hypersusceptibility mechanism of Tenofovir-resistant HIV to EFdA. Retrovirology 10, 65. https://doi.org/10.1186/1742-4690-10-65

Miller, M.D., 2004. K65R, TAMs and tenofovir. AIDS Rev. 6, 22-33.

Muftuoglu, Y., Sohl, C.D., Mislak, A.C., Mitsuya, H., Sarafianos, S.G., Anderson, K.S., 2014. Probing the molecular mechanism of action of the HIV-1 reverse transcriptase inhibitor 4'-ethynyl-2-fluoro-2'-deoxyadenosine (EFdA) using presteady-state kinetics. Antiviral Res. 106, 1-4. https://doi.org/10.1016/j.antiviral.2014.03.001

Murphey-Corb, M., Rajakumar, P., Michael, H., Nyaundi, J., Didier, P.J., Reeve, A.B., Mitsuya, H., Sarafianos, S.G., Parniak, M.A., 2012. Response of Simian Immunodeficiency Virus to the Novel Nucleoside Reverse Transcriptase Inhibitor 4'Ethynyl-2-Fluoro-2'-Deoxyadenosine In Vitro and In Vivo . Antimicrob. Agents Chemother. 56, 4707-4712. https://doi.org/10.1128/aac.00723-12

Naeger, L.K., Struble, K.A., 2006. Effect of baseline protease genotype and phenotype on HIV response to atazanavir/ritonavir in treatment-experienced patients. Aids 20, 847-853. https://doi.org/10.1097/01.aids.0000218548.77457.76

Nakata, H., Amano, M., Koh, Y., Kodama, E., Yang, G., Bailey, C.M., Kohgo, S., Hayakawa, H., Matsuoka, M., Anderson, K.S., Cheng, Y.-C.Y.-C., Mitsuya, H., 2007. Activity against Human Immunodeficiency Virus Type 1, Intracellular Metabolism, and Effects on Human DNA Polymerases of 4'-Ethynyl-2-Fluoro-2'Deoxyadenosine. Antimicrob. Agents Chemother. 51, 2701-2708. https://doi.org/10.1128/AAC.00277-07

Ndongwe, T.P., Adedeji, A.O., Michailidis, E., Ong, Y.T., Hachiya, A., Marchand, B., Ryan, E.M., Rai, D.K., Kirby, K.A., Whatley, A.S., Burke, D.H., Johnson, M., Ding, S., Zheng, Y.M., Liu, S.L., Kodama, E.I., Delviks-Frankenberry, K.A., Pathak, V.K., Mitsuya, H., Parniak, M.A., Singh, K., Sarafianos, S.G., 2012. Biochemical, inhibition and inhibitor resistance studies of xenotropic murine leukemia virusrelated virus reverse transcriptase. Nucleic Acids Res. https://doi.org/10.1093/nar/gkr694

Nitanda, T., Wang, X., Kumamoto, H., Haraguchi, K., Tanaka, H., Cheng, Y.C., Baba, M., 2005. Anti-human immunodeficiency virus type 1 activity and resistance profile of 2',3'-didehydro-3'-deoxy-4'-ethynylthymidine in vitro. Antimicrob. Agents Chemother. 49, 3355-3360. https://doi.org/10.1128/AAC.49.8.3355-3360.2005

Ochsenbauer-Jambor, C., Jones, J., Heil, M., Zammit, K.P., Kutsch, O., 2006. T-cell line 
for HIV drug screening using EGFP as a quantitative marker of HIV-1 replication. Biotechniques. https://doi.org/10.2144/000112072

Oliveira, M., Brenner, B.G., Xu, H., Ibanescu, R.I., Mesplède, T., Wainberg, M.A., 2017. $\mathrm{M} 184 \mathrm{I} / \mathrm{V}$ substitutions and $\mathrm{E} 138 \mathrm{~K} / \mathrm{M} 184 \mathrm{I} / \mathrm{V}$ double substitutions in HIV reverse transcriptase do not significantly affect the antiviral activity of EFdA. J. Antimicrob. Chemother. https://doi.org/10.1093/jac/dkx280

Pear, W.S., Nolan, G.P., Scott, M.L., Baltimore, D., 1993. Production of high-titer helper-free retroviruses by transient transfection. Proc. Natl. Acad. Sci. U. S. A. https://doi.org/10.1073/pnas.90.18.8392

Pennings, P.S., 2013. HIV drug resistance: Problems and perspectives. Infect. Dis. Rep. https://doi.org/10.4081/idr.2013.s1.e5

Petrella, M., Oliveira, M., Moisi, D., Detorio, M., Brenner, B.G., Wainberg, M.A., 2004. Differential maintenance of the M184V substitution in the reverse transcriptase of human immunodeficiency virus type 1 by various nucleoside antiretroviral agents in tissue culture. Antimicrob. Agents Chemother. 48, 4189-4194. https://doi.org/10.1128/AAC.48.11.4189-4194.2004

Platt, E.J., Bilska, M., Kozak, S.L., Kabat, D., Montefiori, D.C., 2009. Evidence that Ecotropic Murine Leukemia Virus Contamination in TZM-bl Cells Does Not Affect the Outcome of Neutralizing Antibody Assays with Human Immunodeficiency Virus Type 1. J. Virol. https://doi.org/10.1128/jvi.00709-09

Platt, E.J., Wehrly, K., Kuhmann, S.E., Chesebro, B., Kabat, D., 1998. Effects of CCR5 and CD4 Cell Surface Concentrations on Infections by Macrophagetropic Isolates of Human Immunodeficiency Virus Type 1. J. Virol. https://doi.org/10.1128/jvi.72.4.2855-2864.1998

Reed, L.J., Muench, H., 1938. A simple method of estimating fifty percent end points. Am J Hyg 27, 493-497.

Rhee, S.-Y., 2003. Human immunodeficiency virus reverse transcriptase and protease sequence database. Nucleic Acids Res. 31, 298-303. https://doi.org/10.1093/nar/gkg100

Rosa, A., Chande, A., Ziglio, S., De Sanctis, V., Bertorelli, R., Goh, S.L., McCauley, S.M., Nowosielska, A., Antonarakis, S.E., Luban, J., Santoni, F.A., Pizzato, M., 2015. HIV-1 Nef promotes infection by excluding SERINC5 from virion incorporation. Nature. https://doi.org/10.1038/nature15399

Salie, Z.L., Kirby, K.A., Michailidis, E., Marchand, B., Singh, K., Rohan, L.C., Kodama, E.N., Mitsuya, H., Parniak, M.A., Sarafianos, S.G., 2016. Structural basis of HIV inhibition by translocation-defective RT inhibitor 4'-ethynyl-2-fluoro-2'deoxyadenosine (EFdA). Proc. Natl. Acad. Sci. 113, 9274-9279. https://doi.org/10.1073/pnas. 1605223113

Sarafianos, S.G., Clark, A.D., Tuske, S., Squire, C.J., Das, K., Sheng, D., Ilankumaran, P., Ramesha, A.R., Kroth, H., Sayer, J.M., Jerina, D.M., Boyer, P.L., Hughes, S.H., Arnold, E., 2003. Trapping HIV-1 reverse transcriptase before and after 
translocation on DNA. J. Biol. Chem. https://doi.org/10.1074/jbc.M212911200

926

927

928

929

930

931

932

933

934

935

936

937

938

939

940

941

942

943

944

945

946

947

948

949

950

951

952

953

954

955

956

957

958

959

960

961

962

963

964

965

966

Sarafianos, S.G., Das, K., Tantillo, C., Clark, A.D., Ding, J., Whitcomb, J.M., Boyer, P.L., Hughes, S.H., Arnold, E., 2001. Crystal structure of HIV-1 reverse transcriptase in complex with a polypurine tract RNA:DNA. EMBO J. 20, 14491461. https://doi.org/10.1093/emboj/20.6.1449

Schinazi, R.F., Lloyd, R.M., Nguyen, M.H., Cannon, D.L., McMillan, A., Ilksoy, N., Chu, C.K., Liotta, D.C., Bazmi, H.Z., Mellors, J.W., 1993. Characterization of human immunodeficiency viruses resistant to oxathiolane-cytosine nucleosides. Antimicrob. Agents Chemother. 37, 875-881. https://doi.org/10.1128/AAC.37.4.875

Schuckmann, M.M., Marchand, B., Hachiya, A., Kodama, E.N., Kirby, K.A., Singh, K., Sarafianos, S.G., 2010. The N348I mutation at the connection subdomain of HIV-1 reverse transcriptase decreases binding to nevirapine. J. Biol. Chem. https://doi.org/10.1074/jbc.M110.153783

Schuurman, R., Nijhuis, M., Van Leeuwen, R., Schipper, P., De Jong, D., Collis, P., Danner, S.A., Mulder, J., Loveday, C., Christopherson, C., Kwok, S., Sninsky, J., Boucher, C.A.B., 1995. Rapid changes in human immunodeficiency virus type $1 \mathrm{rna}$ load and appearance of drug-resistant virus populations in persons treated with lamivudine (3tc). J. Infect. Dis. 171, 1411-1419.

https://doi.org/10.1093/infdis/171.6.1411

Shanmugasundaram, U., Kovarova, M., Ho, P.T., Schramm, N., Wahl, A., Parniak, M.A., Garcia, J.V., 2016. Efficient inhibition of HIV replication in the gastrointestinal and female reproductive tracts of humanized BLT mice by EFdA. PLoS One 11, e0159517. https://doi.org/10.1371/journal.pone.0159517

Singh, K., Marchand, B., Rai, D.K., Sharma, B., Michailidis, E., Ryan, E.M., Matzek, K.B., Leslie, M.D., Hagedorn, A.N., Li, Z., Norden, P.R., Hachiya, A., Parniak, M.A., Xu, H.T., Wainberg, M.A., Sarafianos, S.G., 2012. Biochemical mechanism of HIV1 resistance to rilpivirine. J. Biol. Chem. https://doi.org/10.1074/jbc.M112.398180

Sohl, C.D., Singh, K., Kasiviswanathan, R., Copeland, W.C., Mitsuya, H., Sarafianos, S.G., Anderson, K.S., 2012. Mechanism of interaction of human mitochondrial DNA polymerase $\mathrm{Y}$ with the novel nucleoside reverse transcriptase inhibitor 4'-ethynyl-2fluoro- 2'-deoxyadenosine indicates a low potential for host toxicity. Antimicrob. Agents Chemother. 56, 1630-1634. https://doi.org/10.1128/AAC.05729-11

Stoddart, C.A., Galkina, S.A., Joshi, P., Kosikova, G., Moreno, M.E., Rivera, J.M., Sloan, B., Reeve, A.B., Sarafianos, S.G., Murphey-Corb, M., Parniak, M.A., 2015. Oral administration of the nucleoside EFdA (4'-ethynyl-2-fluoro-2'-deoxyadenosine) provides rapid suppression of HIV viremia in humanized mice and favorable pharmacokinetic properties in mice and the rhesus macaque. Antimicrob. Agents Chemother. 59, 4190-4198. https://doi.org/10.1128/AAC.05036-14

Tachedjian, G., Aronson, H.E.G., De Los Santos, M., Seehra, J., McCoy, J.M., Goff, S.P., 2003. Role of residues in the tryptophan repeat motif for HIV-1 reverse transcriptase dimerization. J. Mol. Biol. 326, 381-396. https://doi.org/10.1016/S0022-2836(02)01433-X 
Tachedjian, G., French, M., Mills, J., 1998. Coresistance to zidovudine and foscarnet is associated with multiple mutations in the human immunodeficiency virus type 1 reverse transcriptase. Antimicrob. Agents Chemother. 42, 3038-3043.

Takeuchi, Y., McClure, M.O., Pizzato, M., 2008. Identification of Gammaretroviruses Constitutively Released from Cell Lines Used for Human Immunodeficiency Virus Research. J. Virol. https://doi.org/10.1128/jvi.01726-08

Tang, J., Do, H.T., Huber, A.D., Casey, M.C., Kirby, K.A., Wilson, D.J., Kankanala, J., Parniak, M.A., Sarafianos, S.G., Wang, Z., 2019. Pharmacophore-based design of novel 3-hydroxypyrimidine-2,4-dione subtypes as inhibitors of HIV reverse transcriptase-associated RNase $\mathrm{H}$ : Tolerance of a nonflexible linker. Eur. J. Med. Chem. https://doi.org/10.1016/j.ejmech.2019.01.081

Tang, J., Kirby, K.A., Huber, A.D., Casey, M.C., Ji, J., Wilson, D.J., Sarafianos, S.G., Wang, Z., 2017. 6-Cyclohexylmethyl-3-hydroxypyrimidine-2,4-dione as an inhibitor scaffold of HIV reverase transcriptase: Impacts of the $3-\mathrm{OH}$ on inhibiting RNase $\mathrm{H}$ and polymerase. Eur. J. Med. Chem. https://doi.org/10.1016/j.ejmech.2017.01.041

Tisdale, M., Kemp, S.D., Parry, N.R., Larder, B.A., 1993. Rapid in vitro selection of human immunodeficiency virus type 1 resistant to 3'-thiacytidine inhibitors due to a mutation in the YMDD region of reverse transcriptase. Proc. Natl. Acad. Sci. 90, 5653-5656. https://doi.org/10.1073/pnas.90.12.5653

Van Cor-Hosmer, S.K., Daddacha, W., Kelly, Z., Tsurumi, A., Kennedy, E.M., Kim, B., 2012. The impact of molecular manipulation in residue 114 of human immunodeficiency virus type- 1 reverse transcriptase on dNTP substrate binding and viral replication. Virology 422, 393-401. https://doi.org/10.1016/j.virol.2011.11.004

Vernekar, S.K. V., Tang, J., Wu, B., Huber, A.D., Casey, M.C., Myshakina, N., Wilson, D.J., Kankanala, J., Kirby, K.A., Parniak, M.A., Sarafianos, S.G., Wang, Z., 2017. Double-Winged 3-Hydroxypyrimidine-2,4-diones: Potent and Selective Inhibition against HIV-1 RNase H with Significant Antiviral Activity. J. Med. Chem. https://doi.org/10.1021/acs.jmedchem.7b00440

von Wyl, V., Ehteshami, M., Demeter, L.M., Bürgisser, P., Nijhuis, M., Symons, J., Yerly, S., Böni, J., Klimkait, T., Schuurman, R., Ledergerber, B., Götte, M., Günthard, H.F., 2010. HIV-1 Reverse Transcriptase Connection Domain Mutations: Dynamics of Emergence and Implications for Success of Combination Antiretroviral Therapy. Clin. Infect. Dis. 51, 620-628. https://doi.org/10.1086/655764

Wainberg, M.A., Zaharatos, G.J., Brenner, B.G., 2011. Development of Antiretroviral Drug Resistance. N. Engl. J. Med. https://doi.org/10.1056/nejmra1004180

Wainburg, M.A., 2004. The impact of the M184V substitution on drug resistance and viral fitness. Expert Rev. Anti. Infect. Ther. 2, 147-151. https://doi.org/10.1586/14787210.2.1.147

Wang, L., Tang, J., Huber, A.D., Casey, M.C., Kirby, K.A., Wilson, D.J., Kankanala, J., Parniak, M.A., Sarafianos, S.G., Wang, Z., 2018. 6-Biphenylmethyl-3- 
1008

1009

1010

1011

1012

1013

1014

1015

1016

1017

1018

1019

1020

1021

1022

1023

1024

1025

1026

1027

1028

1029

1030

1031

1032

1033

1034

1035

hydroxypyrimidine-2,4-diones potently and selectively inhibited HIV reverse transcriptase-associated RNase H. Eur. J. Med. Chem.

https://doi.org/10.1016/j.ejmech.2018.07.035

Wei, X., Decker, J.M., Liu, H., Zhang, Z., Arani, R.B., Kilby, J.M., Saag, M.S., Wu, X., Shaw, G.M., Kappes, J.C., 2002. Emergence of resistant human immunodeficiency virus type 1 in patients receiving fusion inhibitor (T-20) monotherapy. Antimicrob. Agents Chemother. https://doi.org/10.1128/AAC.46.6.1896-1905.2002

Wu, V.H., Smith, R.A., Masoum, S., Raugi, D.N., Ba, S., Seydi, M., Grobler, J.A., Gottlieb, G.S., 2017. MK-8591 (4'-ethynyl-2-fluoro-2'-deoxyadenosine) exhibits potent activity against HIV-2 isolates and drug-resistant HIV-2 mutants in culture. Antimicrob. Agents Chemother. 61, e00744-17. https://doi.org/10.1128/AAC.0074417

Xu, H.-T., Asahchop, E.L., Oliveira, M., Quashie, P.K., Quan, Y., Brenner, B.G., Wainberg, M.A., 2011. Compensation by the E138K Mutation in HIV-1 Reverse Transcriptase for Deficits in Viral Replication Capacity and Enzyme Processivity Associated with the M184I/V Mutations. J. Virol. 85, 11300-11308. https://doi.org/10.1128/JVI.05584-11

Yang, G., Wang, J., Cheng, Y., Dutschman, G.E., Tanaka, H., Baba, M., Cheng, Y.C., 2008. Mechanism of inhibition of human immunodeficiency virus type 1 reverse transcriptase by a stavudine analogue, 4'-ethynyl stavudine triphosphate. Antimicrob. Agents Chemother. 52, 2035-2042. https://doi.org/10.1128/AAC.00083-08

Zhang, D., Caliendo, A.M., Eron, J.J., DeVore, K.M., Kaplan, J.C., Hirsch, M.S., D'Aquila, R.T., 1994. Resistance to 2',3'-dideoxycytidine conferred by a mutation in codon 65 of the human immunodeficiency virus type 1 reverse transcriptase. Antimicrob. Agents Chemother. 38, 282-287. https://doi.org/10.1128/AAC.38.2.282 